\title{
MTR 7307
}

\section{MMSTLR \\ Geothermal Energy Resource Development - \\ Reporiting and Monitoring Sustem}

\section{ARNOLD. COHEN}

\section{FEBRUARY1977}
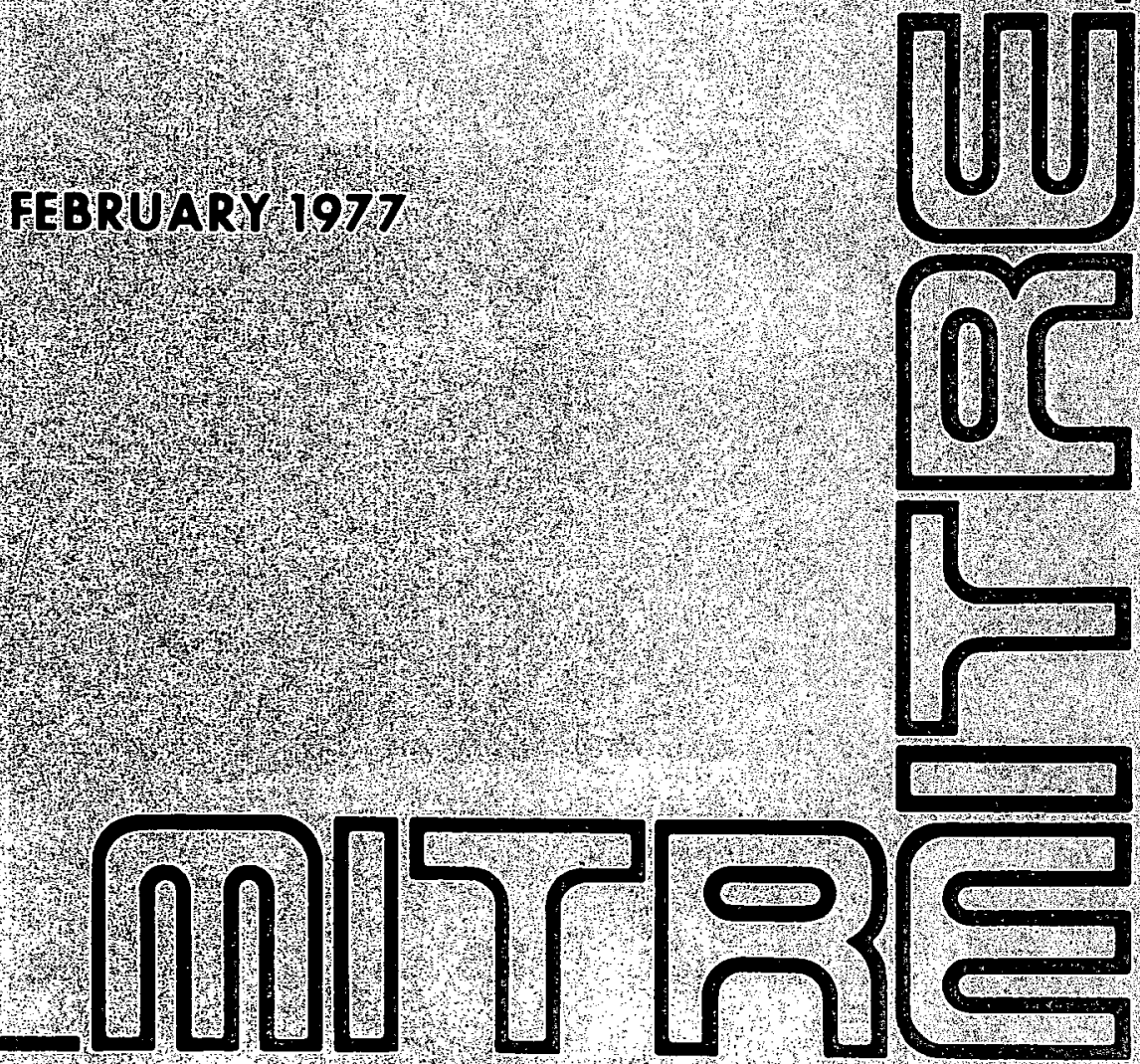


\section{DISCLAIMER}

This report was prepared as an account of work sponsored by an agency of the United States Government. Neither the United States Government nor any agency Thereof, nor any of their employees, makes any warranty, express or implied, or assumes any legal liability or responsibility for the accuracy, completeness, or usefulness of any information, apparatus, product, or process disclosed, or represents that its use would not infringe privately owned rights. Reference herein to any specific commercial product, process, or service by trade name, trademark, manufacturer, or otherwise does not necessarily constitute or imply its endorsement, recommendation, or favoring by the United States Government or any agency thereof. The views and opinions of authors expressed herein do not necessarily state or reflect those of the United States Government or any agency thereof. 


\section{DISCLAIMER}

Portions of this document may be illegible in electronic image products. Images are produced from the best available original document. 


\title{
Geothermal Energy Resource Development - Reporting and Monitoring System
}

\author{
ARNOLD COHEN
}

FEBRUARY 1977

CONTRACT SPONSOR CONTRACT NO.

PROJECT NO.

DEPT.
ERDA/DGE

$E(49 \cdot 18) \cdot 2268$

$391 \mathrm{G}$

W.52
THE MITRE CORPORATION METREK DIVISION
This document was prepared for suthorized distribution. it has not been approved for public release. 

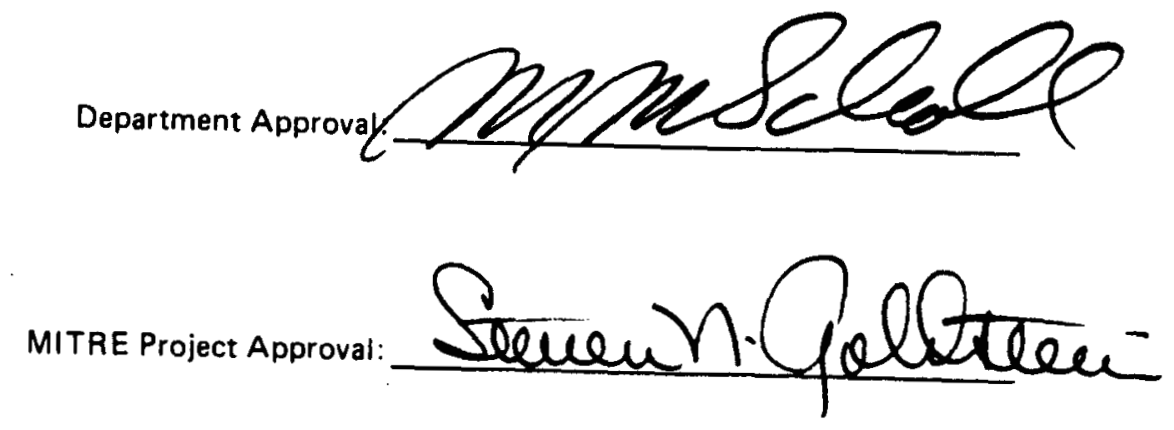

ii 


\section{ABSTRACT}

A Monitoring System is described for reporting, in a timely and comprehensive fashion, the important aspects of the development and utilization of geothermal energy in the United States.

The Federal program for geothermal energy addresses technological, environmental, institutional, economic and financial problems. The system for monitoring geothermal resource development has been designed to measure progress in developing geothermal energy on line and progress in enabling geothermal resources for development, thereby increasing the potential for future exploitation of geothermal resources, as a consequence of successes in the Federal program in solving technological, environmental, institutional, economic and financial problems that currently impede exploitation of geothermal resources.

The key indicator of progress in the development of geothermal energy will be "power on line." Projections of power on line will signal deviations from national goals with sufficient warning time to effect corrective action. Correlation of Federal programs with national progress indicators will show where corrective action is needed.

Preliminary indicators of geothermal resource development, based on very limited data, are presented. The analyses are illustrative rather than definitive. Some conclusions are drawn from these analyses. 


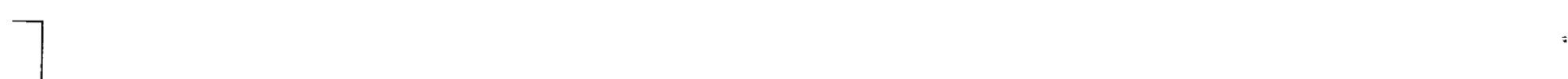

.

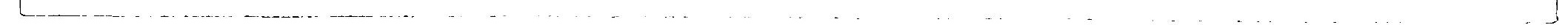

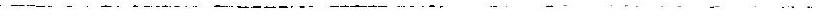




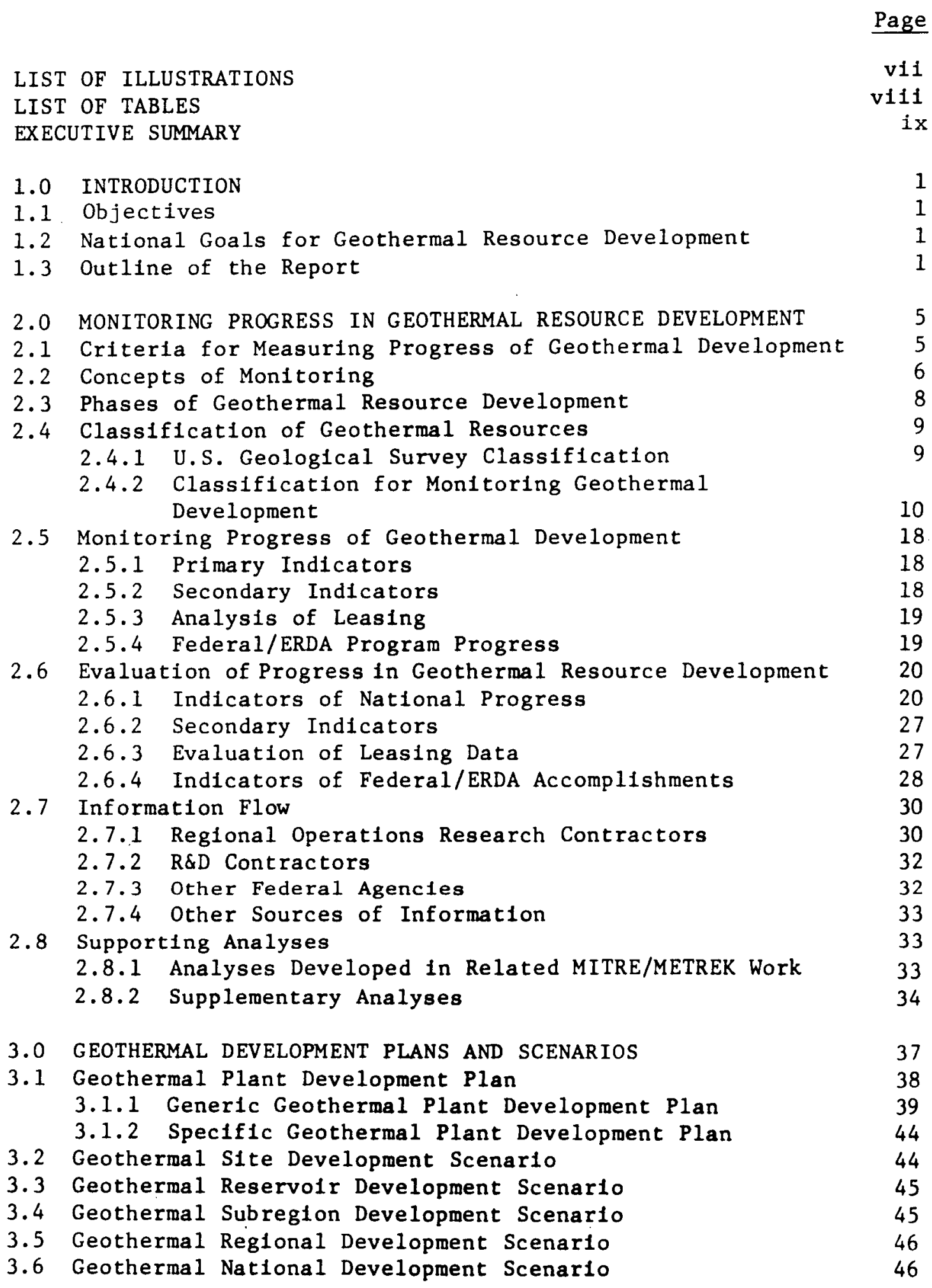


TABLE OF CONTENTS (CONCLUDED)

$\underline{\text { Page }}$

4.0 IMPLEMENTATION

4.1 Implementation Plan

4.1.1 Formulation and Estimation of Preliminary

Indicators

47

47

4.1.2 Development of the Data Base

48

48

4.2 Preliminary Implementation

51

4.2.1 Description of Data Used

51

4.2.2 Analysis of Data

56

4.2.3 Estimates of Power On Line

59

5.0 SUMMARY AND CONCLUSIONS

63

REFERENCES

67

APPENDIX I: ANALYSIS OF LEASING DATA 


\section{LIST OF ILLUSTRATIONS}

$\underline{\text { Page }}$

Figure Number

E-1 ASSIGNMENT OF GEOTHERMAL RESOURCES TO PHASES OF DEVELOPMENT (SCHEMATIC--NOT TO SCALE)

$\mathrm{xV}$

E-2 PROGRESSIVE DEVELOPMENT OF GEOTHERMAL RESOURCES

xvi

E-3 POTENTIAL GEOTHERMAL POWER ON LINE (MW $)_{\text {) }}$ xxvii

1 ASSIGNMENT OF GEOTHERMAL RESOURCES TO PHASES OF DEVELOPMENT (SCHEMATIC--NCT TO SCALE)

PROGRESSIVE DEVELOPMENT OF GEOTHERMAL RESOURCES

DEVELOPMENT OF GEOTHERMAL ENERGY--INFORMATION FLOW

SAMPLE GENERIC GEOTHERMAL PLANT DEVELOPMENT

PLAN (NUMBERS TENTATIVE)

SAMPLE GENERIC GEOTHERMAL PLANT DEVELOPMENT PLAN--MILESTONES

NOMINAL LEASE PRICE VS. TEMPERATURE--SAMPLE RELATIONSHIP 


\section{LIST OF TABLES}

$\underline{\text { Page }}$

Table Number

$E-I$

I

II

I I I

IV

V

VI

VII

VIII

IX

$\mathrm{X}$

$\mathrm{XI}$
CURRENT NATIONAL GOALS FOR GEOTHERMAL ENERGY DEVELOPMENT $\mathrm{x}$

CURRENT NATIONAL GOALS FOR GEOTHERMAL ENERGY DEVELOPMENT

CLASSIFICATION OF GEOTHERMAL RESOURCES

FOR MONITORING DEVELOPMENT VS USGS

CLASSIFICATION (CIRC 726)

MEASURES OF GEOTHERMAL RESOURCE DEVELOPMENT

PRELIMINARY SOURCES OF DATA FOR MONITORING DEVELOPMENT OF GEOTHERMAL ENERGY

SOURCES OF DATA IN THE SAMPLE GPDP

40

SAMPLE GENERIC GEOTHERMAL PLANT DEVELOPMENT PLAN - MANPOWER SUMMARY

GEOTHERMAL ENERGY PLANTS IN DESIGN OR UNDER CONSTRUCTION $\left(\mathrm{MW}_{\mathrm{e}}\right)$

ELECTRIC UTILITIES--PLANS FOR GEOTHERMAL

POWER DEVELOPMENT

ANNUAL NEW POWER-ON-LINE POTENTIAL OF GEOTHERMAL LEASES ( $\mathrm{MW}_{\mathrm{e}}$ )

60

POTENTIAL GEOTHERMAL POWER ON LINE ( $\mathrm{MW}_{\mathrm{e}}$ )

61

BUREAU OF LAND MANAGEMENT SALES OF KGRA LEASES

75 
EXECUT IVE SUMMARY

OBJECTIVES

A system is described for monitoring, in a timely and comprehensive fashion, the progress of geothermal energy development in the United States. The success of the Federal/ERDA Geothermal Program and the performance of the geothermal industry in responding to the Federal Program will be measured. The system will monitor contributory developments, including $R \& D$, legal, regulatory and institutional factors.

NATIONAL GOALS FOR GEOTHERMAL RESOURCE DEVELOPMENT

Current national goals for geothermal power on 1 ine, ${ }^{\star}$ as stated in ERDA-86, are shown in Table E-I. National goals will undergo refinement as more complete information becomes available.

CRITERIA FOR MEASUR ING PROGRESS OF GEOTHERMAL DEVELOPMENT

The primary criteria for monitoring progress of geothermal energy development are that:

- Success of the development program should be measured against national goals.

- Progress of the development program should be measured in a manner that can provide early indications that the program is behind schedule or is otherwise off course. Lead time must be sufficient to enable corrective action to be taken.

$*$

"The term "power on line" will apply to electric and non-electric applications. 
TABLE E-I

CURRENT NATIONAL GOALS FOR GEOTHERMAL ENERGY DEVELOPMENT*

\begin{tabular}{|l|c|c|c|}
\hline & 1985 & 2000 & 2020 \\
\hline $\begin{array}{c}\text { Electric Capacity (MW) } \\
\text { Electric Applications -- } \\
\text { Energy Equivalent (Quads/yr) }\end{array}$ & 0.5 & 2.9 & 10.4 \\
Direct Applications (Quads/yr) & 0.1 & 4.4 & 8.2 \\
\hline Total Energy (Quads/yr) & 0.6 & 4.4 & 18.6 \\
\hline
\end{tabular}

$\overline{\text { * As stated in ERDA- } 86 .[1]}$ 
CONCEPTS OF MONITORING

Regional scenarios for development of geothermal resources in California have been generated by the Regional Operations Research Contractor for California. National scenarios far development of geothermal resources have been generated by the National Operations Research Contractor, The MITRE Corporation, METREK Division. Scenarios will be refined and updated as more information becomes available. A scenario represents a "possible future" in the development of geothermal resources. In developing a scenario assumptions are made about future actions and events that will affect the course of geothermal development. Positive actions by Federal or state entities may be required to encourage or induce some of these developments.

Several plausible scenarios can be generated. When a scenario emerges as the most preferred, it may be adopted as the national goal for geothermal energy development.

Progress in the national effort to develop geothermal energy is measured by "Indicators of Geothermal Resource Development." Indicators are developed, principally in terms of projected time histories of estimated power on line that can be related to national goals and scenarios.

In contrast to the possible future of the scenarios, indicators of geothermal resource development are, within the limitations imposed by the information that is available to the monitoring activity, 
estimates of the "most likely future" in the development of geothermal energy.

Indicators of near-term progress in geothermal resource development--up to ten years ahead--are derived from known data on geothermal development activities to the extent that they are available to the monitoring activity, Where data are lacking or unavailable, values may be estimated or surrogate data may be used. Future actions, such as construction starts, should not be assumed unless they are clearly indicated and highly probable. When an action occurs in the future, the event will be monitored by an increase in the indicators, reflecting the increase in potential power on line. This is basically how progress is monitored. If a future action or event is assumed in advance, no progress will be shown by the indicators when the action is taken or the event occurs.

Longer-term indicators--more than ten years ahead--cannot be based entirely on known data. Nonetheless, they represent attempts to project the most likely future in geothermal resource development.

For monitoring purposes different procedures are used for estimating the indicator for each "phase of resource development." Geothermal resources undergo a spectrum of development phases from discovery through the time that resources are being used to generate power on line. In order to facilitate analysis to estimate indicators 
of geothermal resource development, development activities are divided into six discrete phases. They are:

Phase 0. Resource Identification

Identification of undiscovered resources by evaluation of surface manifestations, geophysical exploration and some drilling (noncommercial exploration).

Phase 1. Development of Resource Exploitability

RD\&D and institutional activities which have an objective to make resources economically, technically and institutionally exploitable.

\section{Phase 2. Enablement of Resources for Development}

Acquisition of leases and permits, filing environmental reports, etc., to enable commercial exploration to commence.

\section{Phase 3. Commercial Exploration}

Exploration on leased lands with the intention to develop exploitable resources commercially.

Phase 4. Construction

Drilling production wells, constructing gathering systems and power plants or distribution systems.

\section{Phase 5. Power on Line}

Use of geothermal resources to provide energy for electric and non-electric applications. 
For the purposes of monitoring, the geothermal resource base ${ }^{*}$ is also subdivided into six segments, associated one-for-one with the six phases of development:

Phase 0: Undiscovered Resources

Phase 1: Known Resources -- Identified but Not Exploitable

Phase 2: Identified, Exploitable Resources

Phase 3: Resources Under Commercial Exploration

Phase 4: Resources Subject to Construction Activities

Phase 5: Resources Producing Power on Line.

The association of resources with the six phases of development is in a continual state of flux, illustrated schematically in Figure E-1. The total resource, represented by the area under the histogram, is relatively constant, depleting slowly as the resources are exhausted in Phase 5. Thus an increase in resources under active commercial exploration in Phase $3\left(\Delta_{3}\right.$ in Figure E-1), for example, is balanced by equivalent decreases in prior phases, possibly from Phase $2\left(\Delta_{2}\right)$ and/or Phase $0\left(\Delta_{0}\right)$. This is illustrated by the hatched portions of the histogram.

The overall purpose of the geothermal development program is to move resources to higher phases, ultimately to bring them on line. The promotion of resources is illustrated in Figure E-2.

\footnotetext{
*Geothermal Resource Base: the stored heat above $15^{\circ} \mathrm{C}$ to a depth of 10 kilometers -- U.S. Geological Survey.
} 


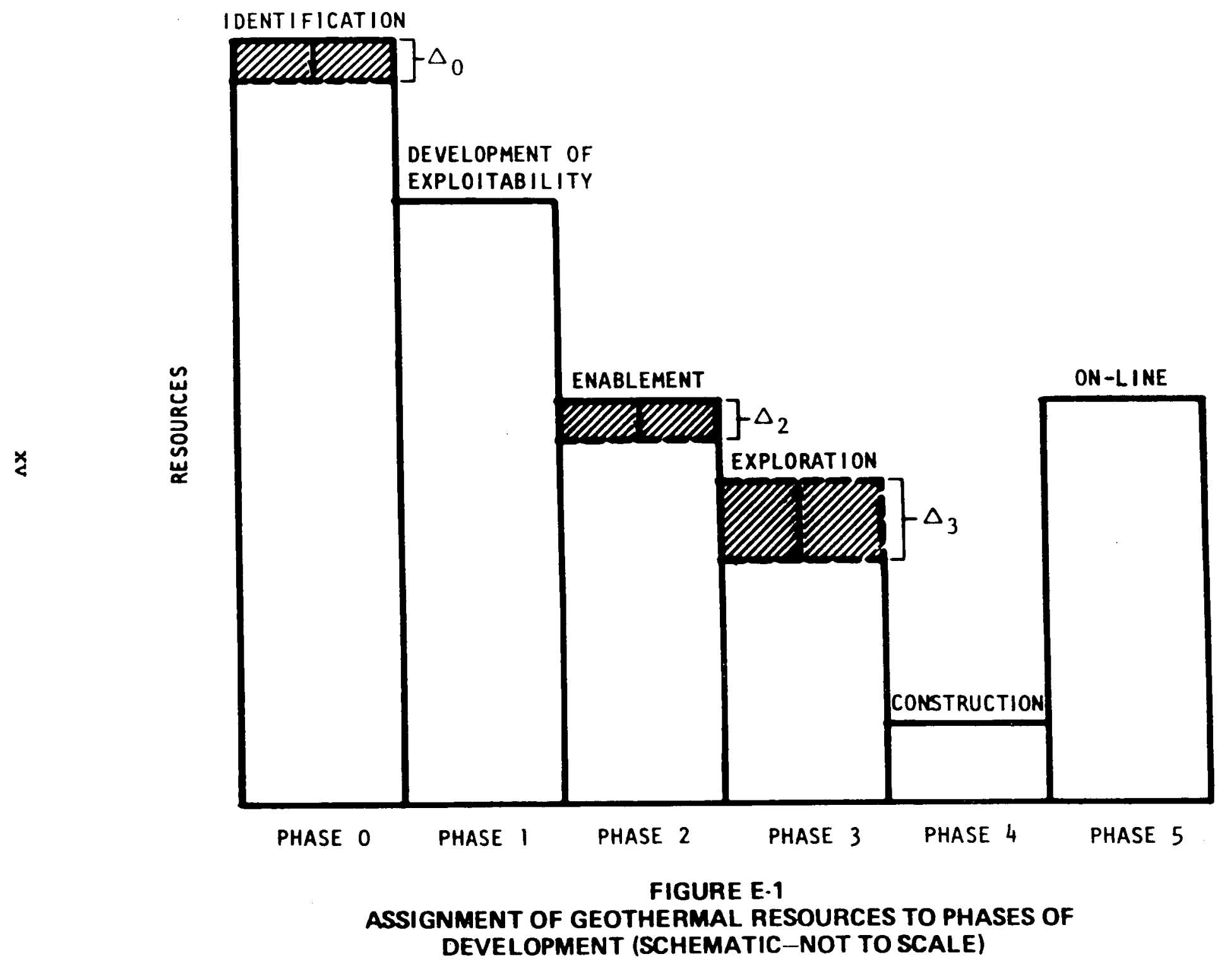




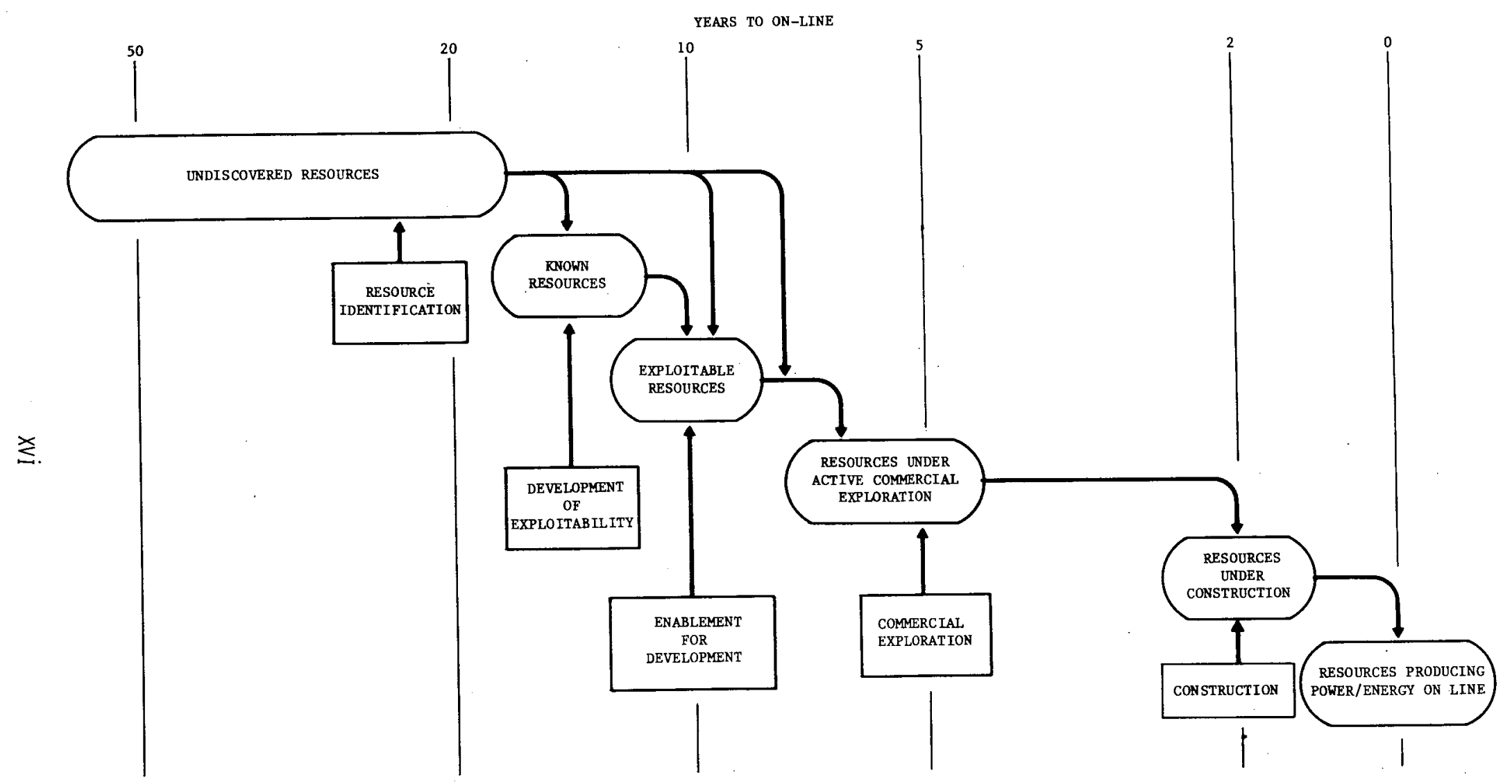

FIGURE E-2
PROGRESSIVE DEVELOPMENT OF GEOTHERMAL RESOURCES 
MONITORING OF PROGRESS IN GEOTHERMAL DEVELOPMENT

Monitoring progress of efforts to develop geothermal energy requires that suitable indicators of resource development be devised. The types of indicators required are discussed below.

\section{Primary Indicators}

The primary indicators for measuring progress in achieving national goals will be actual and projected achievements of power on line.

The ultimate measure of success, actual power on line measured in Phase 5, does not provide any lead time to enable adjustments to be made that will lead toward attainment of national goals. In order to provide adequate warning that the national effort may be falling behind schedule, projections of future power on line will be derived for Phases 1-4, preceding actual power on line. Indications that the national geothermal effort may fail to meet national goals will be obtained with a lead time of up to 15 years and will enable corrective action to be taken.

Secondary Indicators

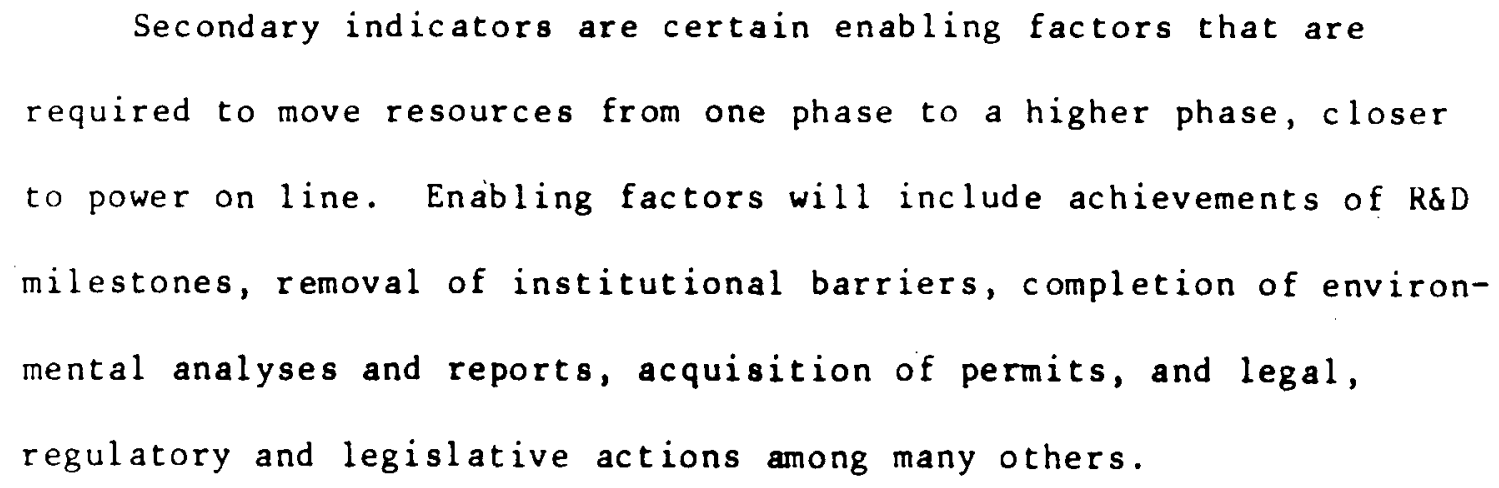


Individually, these enabling factors may not result in incrementing the primary indicators, although each factor represents progress in the development of geothermal energy. Progress is therefore monitored by tracking the accumulation of the required sets of enabling factors that enable resources to move up to a higher phase of development.

Analysis of Leasing Data

Leasing data will be analyzed to assess the implications for geothermal resource development. The potential for power on line of existing leases and scheduled lease sales will provide a check or upper bound on the amount of power that $c$ an be brought on line. Federal/ERDA Program Progress

Progress of the Federal Geothermal Energy program will be monitored in terms of achievement of sub-program milestones and by evaluating the impact of the Federal programs on progress towards achievement of national geothermal energy goals. EVALUATION OF PROGRESS IN GEOTHERMAL RESOURCE DEVELOPMENT The formulation of quantifiable Indicators of Resource Development, which $c$ an be used to evaluate progress in geothermal development, is discussed below.

Indicators of National Progress

To evaluate progress made in the national effort to develop geothermal energy, it is necessary to formulate a set of manageable and quantifiable indicators. Indicators of progress have 
been devised for each phase of resource development, Phase 1

through Phase 5 .

The proposed primary indicators will be described in the

following paragraphs.

Phase 5: Power on line will be the total of all electric power from geothermal resources, total direct application of geothermal energy and energy content of methane generated from geopressured resources.

Phase 4: This indicator is based on the design goal (power on line) for each project under construction but not yet on line. Summing over all projects planned for completion in the same year will yield projections of national achievements in geothermal resource development, two to three years into the future, with a high confidence level, that can be compared directly with national goals.

Phase 3: Phase 3 geothermal resources are close to commercial exploitation. The indicator represents the potential for geothermal power production based on ongoing commercial exploration projects and the probability that the estimated energy potential of the reservoir will be realized. This weighted power potential will be postulated to come on line in a time frame commensurate with the status of the exploration projects. The accumulated potential of all ongoing exploration projects will be a projection of power on line for a period approximately four to ten years into the future.

The exploration data on which this indicator is based will not be readily available as it will usually be held confidential by the developer. Well data from drilling activities on Federal land must be reported to the U.S. Geological Survey, but they nonetheless remain confidential. This problem of obtaining access to data on exploration activities on Federal, state and private lands remains to be solved.

Phase 2: Growth of geothermal energy in competition with other sources of energy will be evaluated by exercising an economic model which will estimate market penetration of each type of energy system based on system costs. 
Phase 1: Resources that are projected to be exploitable at identifiable dates in the future (i.e., future Phase 2 resources) as a consequence of the Federal R\&D program and expected program milestones, will be evaluated by the market penetration model with current Phase 2 resources.

Evaluation of Leasing Data

Data on Federal leases are readily available. These data are useful for monitoring but more detail, which could be otained from the regions, is needed. Data on state leases are available to the monitoring activity only in summary form. Much more detail is required and would be obtainable from state authorities. Data on private leases are currently unavailable -- only crude estimates of the total acreage involved have been obtained. More precise information may be difficult to obtain.

Evaluation of the potential power on line from leases scheduled for future sale will be made. Scheduled Federal lease sales are known through FY 78. Scheduled state lease sales are not known to the monitoring activity, although schedules should be obtainable from state agencies. Little information, if any, can be anticipated on future private lease sales.

The evaluation of potential power on line can be constrained in time by two factors:

1. The time line for initial development of a hydrothermal reservoir, from preliminary geophysical exploration through power on line, is about 9 to 10 years.

2. Under current law Federal leases will be terminated unless drilling is commenced within ten years and power is being generated in commercial quantities within 15 years of lease date. 
Indicators of Federal/ERDA Accomplishments

Important milestones of the Federal RD\&D program, which have significant impact on the achievement of national goals, will be identified with the Interagency Geothermal Coordinating Council * and will be singled out for special attention.

Assessment of the impact of the Federal Geothermal Program must be measured in terms of the achievement of national goals. Current achievements are monitored by Phase 5 indicators of geothermal power on line.

Indicators developed in Phases 3 and 4 are also measures of the magnitude of industry activities in developing geothermal energy and as such are measures of industry response to Federal RD\&D programs. Other measures of industry response to Federal programs will include:

- Uses of the Resources Development Fund,

- Application of Federally financed technology,

- Achievements and potential for geothermal resource development that are a direct consequence of the achievement of milestones in the Federal programs,

- Industry development activities on resources enabled for development by Federal program successes,

- Impact of demonstration projects and application of the technology demonstrated.

The Federal Geothermal Energy Program will be correlated with the industry response to the program and with progress in achieving national goals for geothermal energy development. This will aid

*Formerly the Geothermal Advisory Council

$\mathrm{xx1}$ 
in identifying the needed remedial action to modify Federal plans and programs that will help get the national effort back on course for ultimate achievement of national geothermal energy goals. INFORMATION FLOW

For the purposes of monitoring the development of geothermal energy, data may be obtained through:

- Regional Operations Research Contractors (or the National Operations Research Contractor),

- R\&D Contractors,

- Federal Agencies.

\section{Regional Operations Research Contractors}

The Regional Contractor can serve as the principal conduit for information flow from the Region to ERDA. Where no Regional Contractor has been appointed to a Region, the information could be acquired by the National Operations Research Contractor.

The Regional Contractor should be responsible for planning, promotion, analysis, monitoring, and reporting the development and utilization of geothermal energy within the region.

\section{R\&D Contractors}

Information from R\&D Contractors can be obtained through the normal contract reporting procedures to ERDA or Other Federal Agency Sponsors. These data, together with such additional data as are required for monitoring geothermal energy development, should be coordinated at the national level. 
Federal Agencies

Various Federal agencies and branches can be requested directly to provide data under the auspices of the Interagency Geothermal Coordinating Council. In particular it is expected that the U.S. Geological Survey will be able to provide updated estimates of energy potential of lands under exploration. Leasing data needed for monitoring can be obtained directly from the Bureau of Land Management and from the U.S. Forest Service.

\section{IMPLEMENTATION}

The machinery for acquisition of data in support of the monitoring function has not yet been established. The first implementation of the monitoring function has therefore been on an ad hoc basis, utilizing whatever data that could be acquired.

Data on actual activities and plans, mostly in The Geysers, are used where they are available. As surrogates for data on exploration and exploitation activities in 1 iquid hydrothermal resources, leasing data are used to estimate upper bounds on possible development of these resources. Because of the constraints imposed on development of Federal geothermal leases by the Federal Geothermal Leasing Law, as described earlier, it is postulated that existing leases, including state and private leases as well as Federal leases, will be developed during the period through 1990. Except in The Geysers, current plans or intentions to proceed with this development are, for the most part, lacking or unknown. 
A summary of the data follows.

Phase 5: Resources Producing Power on Line

The principal applications of geothermal energy in the United States are the electric generating plants at The Geysers (502 MWe) and heating systems in Klamath Falls, Oregon, (5.6 MWt) and in Boise, Idaho, (9.2 MWt).

Phase 4: Resources Committed to or Under Construction

Current construction of geothermal power plants is mostly at The Geysers. It is assumed in these analyses that power plants on leases in The Geysers will come on line according to the schedules of construction and expansion plans of the utilities.

Other plants in design or under construction include the thermal loop flashed-to-binary test facility at Niland, California, and the thermal loop integrated energy conversion facility at Raft River, Idaho. Production-type wells have been drilled at Salton Sea, Heber, East Mesa, Brawley and Valles Caldera. San Diego Gas and Electric has pursued plans to construct a 50 MWe Demonstration Plant at Heber to come on line in 1980 .

Realistically, considering that the Heber demonstration plant is not yet committed to construction, it will probably not be on $\mathrm{l}$ ine before 1981. Since some development activity has already commenced in the above five reservoirs, it is postulated, in lieu of known plans, that power plants, to the estimated power potential of current leases in these reservoirs, will come on line 
starting in 1981 with the Heber demonstration, and continuing at an assumed uniform rate through 1987.

Phase 3: Resources Under Commercial Exploration

Some exploratory drilling activity is underway at the following reservoirs: Chandler, Arizona; Coso H.S., California; Long Valley, California; Surprise Valley, California; Mountain Home, Idaho; Beowawe, Nevada; Brady's H.S., Nevada; Steamboat Springs, Nevada; Roosevelt (McKean) H.S., Utah; Bingham City, Utah. In view of this known activity, and in lieu of specific data, it is postulated that power plants, to the estimated power potential of current leases in these reservoirs, will come on line during the period 1983-1990. Phase 2: Exploitable (Undeveloped) Resources

MITRE's first effort to estimate market penetration based on an economic model is underway but results are not yet available.

In lieu of market penetration estimates, it is postulated that power plants, to the estimated power potential of currently leased land in reservoirs in which there has been no active exploration, will come on line during a period from 1986 to 1990.

\section{Phase 1: Known Resources}

Projections of Phase 1 resources that become Exploitable Resources (Phase 2) in the future are necessarily highly speculative. They will be analyzed by a market penetration model with Phase 2 resources. The results of these analyses are not available at the time of writing. 
Estimates of Power on Line

Estimated cumulative power on line from existing power on line, construction activities and planned expansion in The Geysers, and from estimates of power on line derived from analyses of lease data, as surrogate data for known exploration and construction activities in liquid hydrothermal reservoirs, is displayed in Figure E-3.

\section{CONCLUSIONS AND RECOMMENDATIONS}

The analysis of available data must be regarded as essentially illustrative and not definitive. Notwithstanding the limitations on the analyses, some conclusions can be drawn.

- The estimates of new power on line each year from 19861990 are about an order of magnitude greater than new power on line each year in the years prior to 1986. The distribution of these estimates is subject to two constraints:

1. The time line to bring new power on line from liquid hydrothermal resources is about 10 years from preliminary exploration. Reasonable assumptions have been made regarding how much earlier some of the estimated power from these resources could be brought on line.

2. The Geothermal Steam Act of 1970 requires that active development of a Federal lease be undertaken within 10 years of lease date and that power should be generated within 15 years.

- About half of the new power on line during the period 1986-1990 is from Federal leases which are subject to the constraint in 2 above. The other half is from private leases which may not be subject to the same constraint but is, however, subject to considerable uncertainty. 


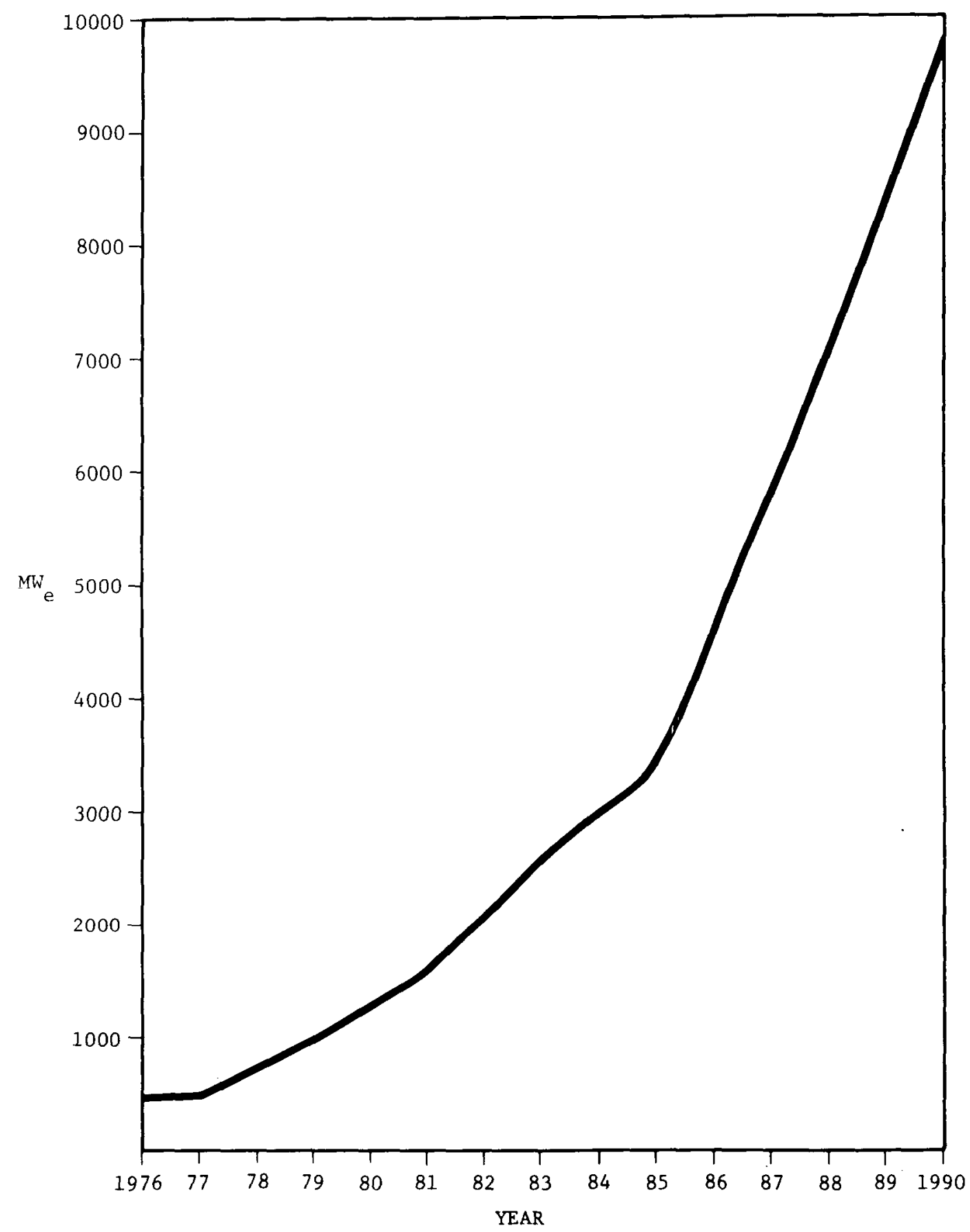

FIGURE E-3

POTENTIAL GEOTHERMAL POWER ON LINE $\left(\mathrm{MW}_{\mathbf{e}}\right)$

xxv11 
- If it is assumed that current leased 1 ands will be developed on a time scale consistent with requirements of the law regarding development of Federal leases, then one may reach unreasonable conclusions regarding potential geothermal power on line in the years 1986-1990.

Certain tasks require early attention and definition:

- Development of detailed data specifications,

- Development, by the National and Regional Contractors, of a specification for machinery to acquire data,

- Selection of a data management system,

- Specification and preliminary implementation of a data base in a form suitable for automated data management. 


\subsection{INTRODUCTION}

\subsection{Objectives}

A system is described for monitoring, in a timely and comprehensive fashion, the progress of geothermal energy development in the United States. Success of the Federal/ERDA Geothermal Program and the performance of the geothermal industry in responding to the Federal Program will be measured. The system will monitor contributory developments, including $R \& D$, legal, regulatory and institutional factors.

\subsection{National Goals for Geothermal Resource Development}

Current national goals for geothermal resource development and power on 1ine, * as stated in ERDA-86, ${ }^{[1]}$ are shown in Table $I$. National goals will undergo refinement as more complete information becomes available.

\subsection{Outline of the Report}

Section 2 of the report presents the structure for monitoring the progress of development of geothermal resources.

Section 3 addresses geothermal development plans and scenarios, ranging from the development plan for a single geothermal plant through site, reservoir, regional and national development scenarios.

ॠThe term "power on line" will apply to electric and non-electric applications. 
TABLE I

CURRENT NATIONAL GOALS FOR GEOTHERMAL ENERGY DEVELOPMENT*

\begin{tabular}{|c|c|c|c|}
\hline & 1985 & 2000 & 2020 \\
\hline Electric Capacity (MW) & 6000 & 39,000 & 140,000 \\
\hline $\begin{array}{l}\text { Electric Applications - - } \\
\text { Energy Equivalent (Quads/yr) }\end{array}$ & 0.5 & 2.9 & 10.4 \\
\hline Direct Applications (Quads/yr) & 0.1 & 1.5 & 8.2 \\
\hline Total Energy (Quads/yr) & 0.6 & 4.4 & 18.6 \\
\hline
\end{tabular}

These goals should be evaluated in relation to scenarios for geothermal resource utilization developed by MITRE and reported In MTR-7220, "Analys1s of Geothermal Energy Development Scenar1os."[2]

$\overline{\text { As stated in ERDA-86 }}{ }^{[1]}$ 
Section 4 describes an implementation plan for the monitoring

function and presents data and analyses that represent a preliminary implement ation. 

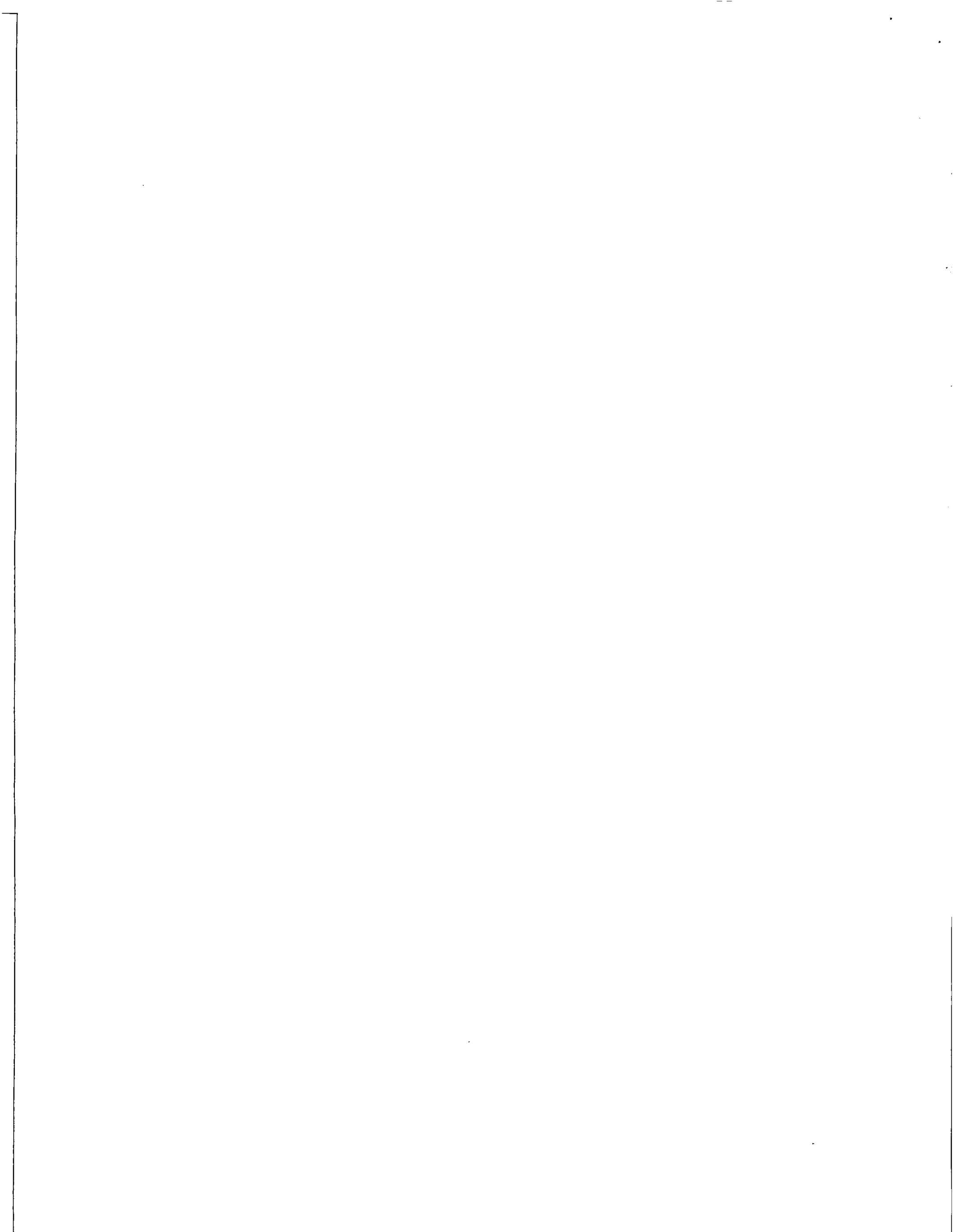


\subsection{MONITORING PROGRESS IN GEOTHERMAL RESOURCE DEVELOPMENT}

The progress of geothermal resource development will be monitored for Federal programs, including ERDA programs, and for the achievement of national goals in developing geothermal energy. Criteria for measuring progress of the national geothermal development effort are defined in Section 2.1. The basic concepts of a proposed methodology for monitoring are described in Section 2.2. Six phases of geothermal resource development are identified, from Phase 0, Resource Identification, to Phase 5, Power on Line, and are defined in Section 2.3. An associated classification of geothermal resources is described in Section 2.4. Types of indicators for monitoring progress of geothermal development are proposed in Section 2.5 and generic methods for evaluating the indicators are described in Section 2.6. A structure for monitoring progress is described in Section 2.7 and supporting analyses are discussed in Section 2.8.

\subsection{Criteria for Measuring Progress of Geothermal Development}

The primary criteria for monitoring progress of geothermal energy development are that:

- Success of the national effort for geothermal energy development should be measured against national goals.

- Progress of the development program should be measured in a manner that $c$ an provide early indications that the program is behind schedule or is otherwise off course. Lead time must be sufficient to enable corrective action to be taken. 


\subsection{Concepts of Monitoring}

Regional scenarios for development of geothermal resources in California have been generated by the Regional Operations Research Contractor for California. National scenarios for development of geothermal resources have been generated by the National Operations Research Contractor, The MITRE Corporation, METREK Division. Scenarios will be refined and updated as more information becomes available.

A scenario represents a "possible future" in the development of geothermal resources. In developing a scenario, assumptions are made about future actions and events that will affect the course of geothermal development. As sumptions may include future R\&D milestone achievements and the effects on system costs, decisions to commence exploration and construction activities, changes in laws and regulations, and changes in community attitudes. Positive actions by Federal or state entities may be required to encourage or induce some of these developments.

Several plausible scenarios can be generated, each based on a different set of assumptions. As scenarios are updated and refined, one will probably emerge as the preferred or most plausible. This scenario may then be adopted as the national goal for geothermal energy development.

Progress in the national effort to develop geothermal energy is measured by "Indicators of Geothermal Resource Development." 
Indicators are developed, principally in terms of projected time histories of estimated power on line that can be related to national goals and scenarios.

Indicators of geothermal resource development are derived from data on geothermal development activities, including the results of research, development and demonstrations, exploration data and progress in construction, plans of developers and utilities for developing geothermal resources, and from data on the geothermal resources. Analyses will be based on known data to the extent that they are available to the monitoring activity. Where data are lacking or are unavailable, values may be estimated or surrogate data may be used.

In contrast to the possible future of the scenario, indicators of geothermal resource development represent, within the limitations imposed by the information that is available to the monitoring activity, estimates of the "most likely future" in the development of geothermal energy. To the extent that it is possible, indicators of near-term progress--up to about ten years ahead--are based on facts. Future actions, such as construction starts, should not be assumed unless they are clearly indicated and highly probable. When an action occurs in the future, the event will be monitored and will result in an increase in the indicators, reflecting the increase in potential power on line. This is basically how progress is monitored. 
If a future action or event is assumed now, no progress will be shown by the indicators when the action is taken or the event occurs. Longer-term indicators will be projections of resource development more than ten years ahead and cannot be based entirely on currently known data. While some assumptions about the future are necessary, the objective is to project, as far as possible with the techniques and information available, the most 1 ikely future in geothermal energy development.

\subsection{Phases of Geothermal Resource Development}

For monitoring purposes different procedures are used for estimating the indicators for each "phase of resource development." Geothermal resources undergo a spectrum of development phases from discovery through the time that resources are being used to generate power on line. In order to facilitate analysis to estimate indicators of geothermal resource development, development activities are divided into six discrete phases. They are:

Phase 0 . Resource Identification

The process of identifying undiscovered resources by surface manifestations, geophysical exploration and some drilling (noncommercial exploration).

Phase 1. Development of Resource Exploitability

RD\&D and institutional activities which have an objective to make resources economically, technically and institutionally exploitable. 
Phase 2. Enablement of Resources for Development

Acquisition of leases and permits, filing environmental reports, etc., to enable commercial exploration to commence.

Phase 3. Commercial Exploration

Exploration on leased lands with the intention to develop exploitable resources commercially.

Phase 4. Construction

Drilling production wells, constructing gathering systems and power plants or distribution systems

Phase 5. Power On Line

Use of geothermal resources to provide energy for electric and non-electric applications.

2.4 Classification of Geothermal Resources

\subsubsection{U.S. Geological Survey Classification}

The U.S. Geological Survey has adopted a classification of geothermal resources based in part on technological recoverability and in part on the economics of recovery. The classification is described in DOI Geological Survey Circular $726^{[3]}$ and is briefly summarized here.

- Geothermal Resource Base--the stored heat above $15^{\circ} \mathrm{C}$ to a depth of $10 \mathrm{~km}$.

- Geothermal Resources--the stored heat, identified and undiscovered, that is recoverable using current technology, regardless of cost. This is further divided into: 
- Submarginal Geothermal Resources--recoverable at a cost more than twice the current price of competitive energy.

- Paramarginal Geothermal Resources--recoverable at a cost between one and two times the current price of competitive energy.

- Geothermal Reserves--identified resources, recoverable at a cost that is competitive with other sources of energy.

\subsubsection{Classification for Monitoring Geothermal Development}

For the purpose of monitoring national progress in the development of geothermal energy and for relating national progress to the Federal R\&D Program, a different resource classification is appropriate. The geothermal resources are associated with the six phases of resource development in the following way:

Phase 0: Undiscovered Resources--that part of the Geothermal Resource Base (as defined by USGS) that is not Identified.

Phase 1: Known Resources--Identified Geothermal Resources which are not exploitable. Known Resources are those Identified Resources for which technology required for exploitation is not developed, or is not completely developed and Identified Resources for which the technology is developed but for which there are institutional limitations on exploitation. Examples of Known Resources for which technology is not developed would be hot dry rock and geopressured resources. 
Liquid-dominated high-salinity hydrothermal resources would be examples of resources for which technology is not completely developed. As an example of institutional limitations on development of resource, Napa County, California had been operating under an ordinance (expired May 17, 1976) which prohibited production, development or transportation of geothermal power but allowed exploration under strict controls. The county has been considering a new $0 i 1$, Gas and Geothermal Resource Exploration and Development Ordinance which would also have very rigorous conditions. [4] Known Resources represent long-term possibilities for growth. Lead time for development would generally be in excess of 10 years. The resources include the identified part of the USGS Submarginal Geothermal Resources and of the Paramarginal Geothermal Resources and the part of the Geothermal Reserves that is not institutionally enabled.

Phase 2: Exploitable (Pre-Enabled) Resources--Exploitable Geothermal Resources that are not enabled for commercial development. These resources represent medium-to-longterm potential for growth. Lead time for development would generally be about 10 years. Currently, only certain vapor-dominated hydrothermal resources 
and certain low-to-moderate-salinity liquid-dominated hydrothermal resources would be in Phase 2. With further development, it is anticipated that other liquid-dominated hydrothermal resources will be moved up from Phase 1 into Phase 2. These resources include the part of Geothermal Reserves (as defined by USGS) that is institutionally exploitable.

Phase 3: Resources Under Active Commercial Exploration--geothermal resources under active commercial development that are not yet under commercial exploitation. They are resources that are being actively explored with the objective to exploit suitable resources commercially. These resources represent short-term potential for growth with a lead time of 4 to 10 years. They are a part of Geothermal Reserves (as defined by USGS).

Phase 4: Resources Committed To or Under Construction--geothermal resources under commercial exploitation which are not yet on line. They are resources for which exploitation feasibility has been determined, plant design has been completed, environmental reports have been made, financing arranged and construction permits obtained, and a final commitment has been made to exploit the geothermal resource. They represent short-term prospects for growth with a high confidence 
level and a definable time-schedule (two to three years) to bring the geothermal energy on 1 ine. These resources are part of Geothermal Reserves (as defined by USGS).

Phase 5: Resources Producing Power On Line--geothermal resources producing electric power on line, direct applications of geothermal energy, and pipeline gas. They are part of Geothermal Reserves (as defined by USGS).

Table II illustrates the difference in focus between the USGS classification and the six phases discussed in this report. The USGS classification focuses primarily on technological and economic recoverability of the resource. Monitoring national progress in development of geothermal energy, however, requires a much broader assessment of the status of geothermal resource development than merely technological and economic recoverability. The Federal program for geothermal energy addresses technological, environmental, institutional, economic and financial problems, and the principal national goals are stated in terms of power on line (Table I). The classification of geothermal resources into six phases has therefore been designed for the purpose of measuring progress in development of geothermal energy on line and progress in enabling geothermal resources for development, thereby increasing the potential for future exploitation of geothermal resources, as a consequence of 
TABLE II

CLASSIFICATION OF GEOTHERMAL RESOURCES FOR MONITORING DEVELOPMENT

VS .

USGS CLASSIFICATION (CIRC 726)

\begin{tabular}{|l|c|c|}
\hline \multicolumn{1}{|c|}{$\begin{array}{c}\text { Geothermal Resource Base } \\
\text { (USGS) }\end{array}$} & \multicolumn{2}{|c|}{ Six-Phase Resource Classification } \\
\hline \multirow{2}{*}{$\begin{array}{l}\text { Unrecoverable Resources } \\
\text { Recoverable Resources }\end{array}$} & Undiscovered & Identified \\
\cline { 2 - 3 } Submarginal Resources & Phase 0 & Phase 1 \\
Paramarginal Resources & Phase 0 & Phase 1 \\
Reserves & & Phase 1 \\
& & Phase 1 \\
& & Phase 2 \\
& & Phase 3 \\
& & Phase 4 \\
& & Phase 5 \\
\hline
\end{tabular}


successes in the Federal program in solving technological, environmental, institutional, economic and financial problems that currently impede exploitation of geothermal resources.

The association of resources with the six phases of development is in a continual state of $f l u x$, being updated as new data become available. This fluctuation is illustrated schematically in Figure 1. The histogram represents the quantity of geothermal resources in each phase; the total resource, represented by the area under the histogram, is relatively constant, depleting slowly as the resources are exhausted in Phase 5. Thus an increase in resources under active commercial exploration in Phase $3\left(\Delta_{3}\right.$ in Figure 1), for example, is balanced by equivalent decreases in prior phases, possibly from Phase $2\left(\Delta_{2}\right)$ and/or Phase $0\left(\Delta_{0}\right)$. This is illustrated by the hatched portions of the histogram.

The six phases of geothermal development and the promotion of resources from one phase to the next are shown schematically in Figure 2. The assignment of resources into phases is non-overlapping and the phases represent an orderly sequence of development. The overall purpose of the geothermal development program is to effect the movement of resources to higher phases, ultimately to on-line. Resources from Phase 0 may be promoted directly to Phase 2, when identified, if the resource is institutionally and technologically exploitable. Resources identified during the course of commercial exploration could be promoted directly from Phase 0 to Phase 3 . The 


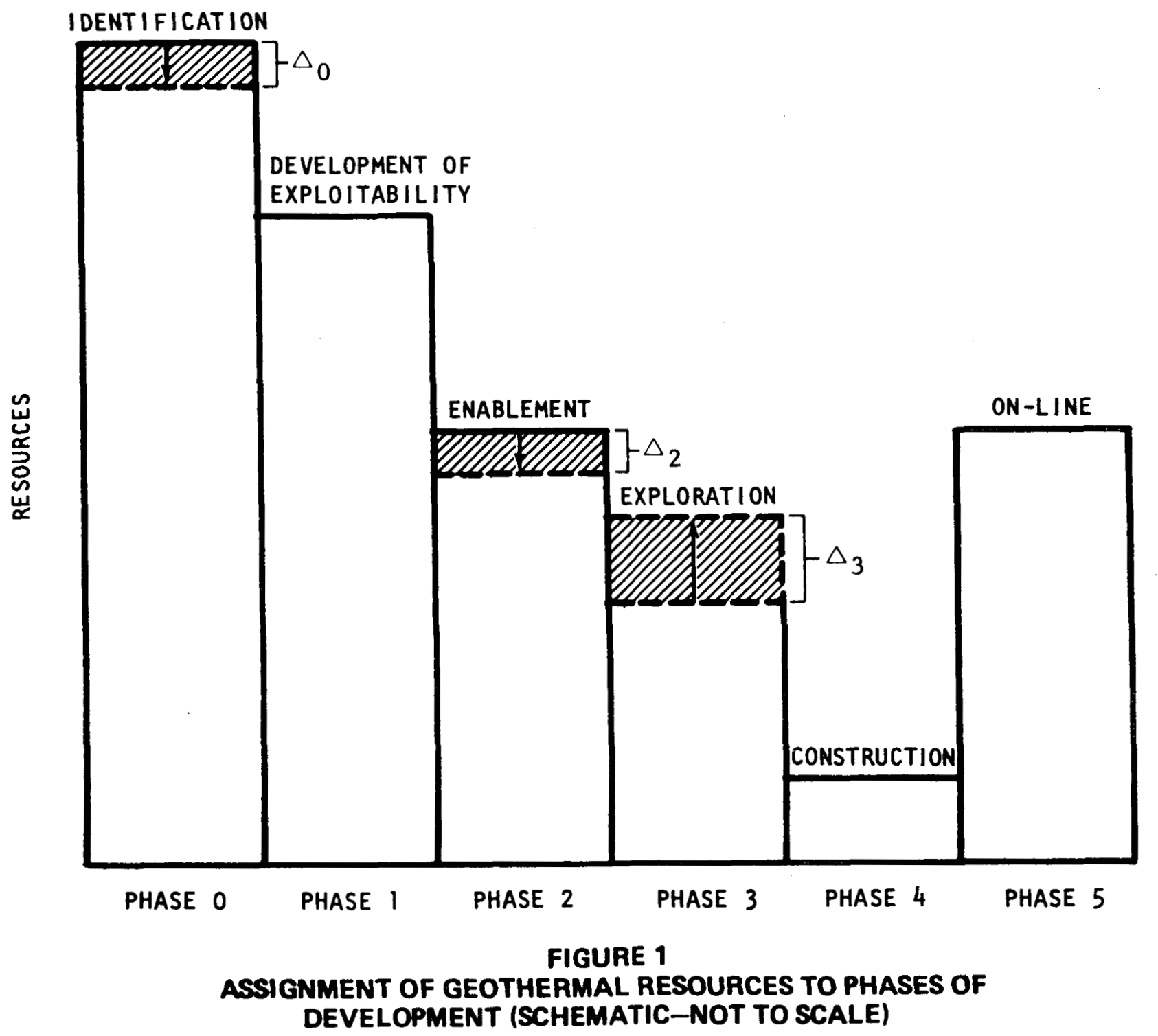




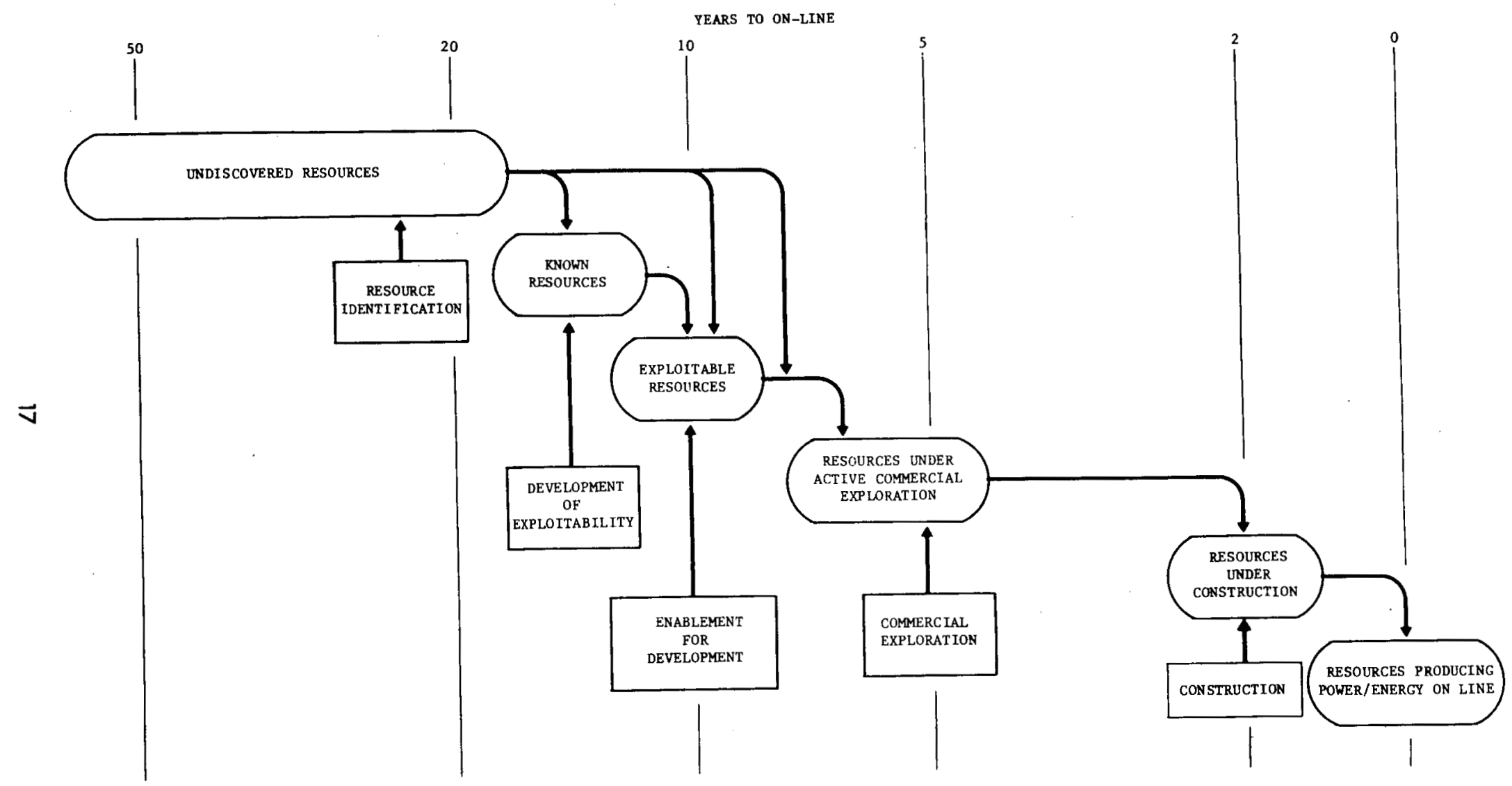

FIGURE 2

PROGRESSIVE DEVELOPMENT OF GEOTHERMAL RESOURCES 
normal progression of resources, however, would be from one phase to the next higher phase.

It should also be recognized that Identified Resources that are expected to be exploitable (Phase 2) may turn out to be other than expected when proven in Phase 3, and may therefore slip back to Phase 1 if unexploitable, or be deleted entirely if nonexistent.

\subsection{Monitoring Progress of Geothermal Development}

\subsubsection{Primary Indicators}

The primary indicators for monitoring progress in achieving national goals will be actual and projected achievements of geothermal power on 1 ine.

The ultimate measure of national success, actual power on 1 ine-measured in Phase 5--is known only as it is achieved and does not provide any lead time to make adjustments aimed toward attainment of national goals.

In order to provide advance warning that the national geothermal development effort may be falling behind schedule, projections of future power on 1 ine will be derived for Phases 1-4, preceding actual power on line. Indications that the national effort may fail to meet national goals will be obtained with a lead time of up to 15 years and will enable corrective action to be taken.

\subsubsection{Secondary Indicators}

Secondary indicators of progress in developing geothermal energy are certain enabling factors that are required to advance geothermal 

geothermal energy goals will be measured in terms of national achievements and the potential for geothermal resource development that is enabled as a direct consequence of success and achievement of milestones in the Federal programs, in terms of industry development activities on resources enabled for development by Federal program successes, and in terms of industry activities directly or in part related to the Geothermal Resources Development Fund (Loan Guaranty Program) and the Demonstrations Program.

\subsection{Evaluation of Progress in Geothermal Resource Development}

\subsubsection{Indicators of National Progress}

Indicators of national progress in geothermal resource development have been devised for each phase of resource development, Phase 1 through Phase 5.

The types of primary indicators proposed are shown in Table III. The exact formulation of each indicator has not yet been developed but generic formulations will be shown in this section. Examples of secondary indicators are also shown in Table III. Specific secondary indicators in general have yet to be defined. In many cases it cannot yet be determined precisely what set of enabling factors is required to promote resources from one phase to another. Likely sources of data for estimating primary indicators and for secondary indicators are shown in Table IV.

The primary indicators have been chosen to measure progress of geothermal resource development in the same terms as the national 
TABLE III

MEASURES OF GEOTHERMAL RESOURCE DEVELOPMENT

\begin{tabular}{|c|c|c|c|c|c|}
\hline & $\begin{array}{l}\text { PHASE } 1 \\
\text { KNOWN } \\
\text { RESOURCES }\end{array}$ & $\begin{array}{l}\text { PHASE } 2 \\
\text { EXPLOITABLE } \\
\text { (PRE-ENABLED) } \\
\text { RESOURCES }\end{array}$ & $\begin{array}{c}\text { PHASE } 3 \\
\text { RESOURCES UNDER } \\
\text { COMMERCIAL } \\
\text { EXPLORATION }\end{array}$ & $\begin{array}{c}\text { PHASE } 4 \\
\text { RESOURCES COMMITTED } \\
\text { TO OR UNDER } \\
\text { CONSTRUCTION }\end{array}$ & $\begin{array}{c}\text { PHASE } 5 \\
\text { RESOURCES PRODUCING } \\
\text { POWER/ENERGY } \\
\text { ON-LINE }\end{array}$ \\
\hline $\begin{array}{l}\text { PRIMARY } \\
\text { INDICATORS }\end{array}$ & $\begin{array}{l}\text { Market Penetration Model } \\
\text { E = E (Future R\&D } \\
\text { Institutional } \\
\text { Pactors, Cest } \\
\text { Effectiveness) }\end{array}$ & 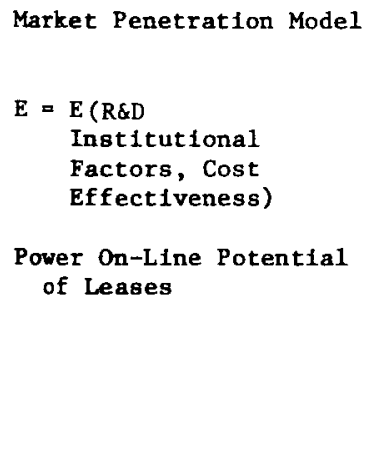 & $\begin{array}{l}\text { Energy Potential of } \\
\text { Exploration } \\
\text { Activities } \\
\text { E = } \\
\begin{aligned} & \text { E(Exploration, } \\
& \text { Legal/Planning } \\
& \text { Enablement) }\end{aligned}\end{array}$ & $\begin{array}{l}\text { Energy Potential of } \\
\text { Production Wells } \\
\text { Drilled } \\
\text { Thermal/Pressure/ } \\
\text { Methane } \\
\\
\text { E = E (Flow, } \\
\text { Temperature, } \\
\text { Pressure, Methane } \\
\text { Content) }\end{array}$ & Power/Energy On-Line \\
\hline $\begin{array}{l}\text { SECONDARY } \\
\text { INDICATORS }\end{array}$ & $\begin{array}{l}\text { R\&D Projects, Milestones } \\
\text { Leg1slation } \\
\text { Regulation } \\
\text { Legal Actions } \\
\text { Act1vities of Action } \\
\text { Groups } \\
\text { Environmental } \\
\text { Standards }\end{array}$ & $\begin{array}{l}\text { Cost-Effectiveness } \\
\text { Analyses } \\
\text { BLM Environmental } \\
\text { Analyses } \\
\text { Land Ownership } \\
\text { Land Use Plans } \\
\text { Water Use Plans/ } \\
\text { Avallabillty } \\
\text { Leasing/Exploration } \\
\text { Permits }\end{array}$ & $\begin{array}{l}\text { Wells drilled - } z \\
\text { Success } \\
\text { Temperature, Pressure, } \\
\text { Methane Content, } \\
\text { Salinity, Flow } \\
\text { Construction Permits - } \\
\text { Type, Size of Plant } \\
\text { Environmenta1 Impact } \\
\text { Reports/Analyses } \\
\text { Partictpants } \\
\text { Availability of } \\
\text { Capital } \\
\text { Demonstrations } \\
\text { Manpower/Equipment/ } \\
\text { Materlals Availability }\end{array}$ & $\begin{array}{l}\text { Type of Application } \\
\text { Wells drilled - } \% \\
\text { Success } \\
\text { Temperature, } \\
\text { Pressure, Sethane } \\
\text { Content, Salinity, } \\
\text { Flow }\end{array}$ & $\begin{array}{l}\text { MWe Electricity } \\
\text { MWt Direct } \\
\text { Application } \\
\text { Pipeline Gas (MW } \\
\text { equivalent) }\end{array}$ \\
\hline
\end{tabular}


TABLE IV

PRELIMINARY SOURCES OF DATA FOR MONITORING DEVELOPMENT OF GEOTHERMAL ENERGY

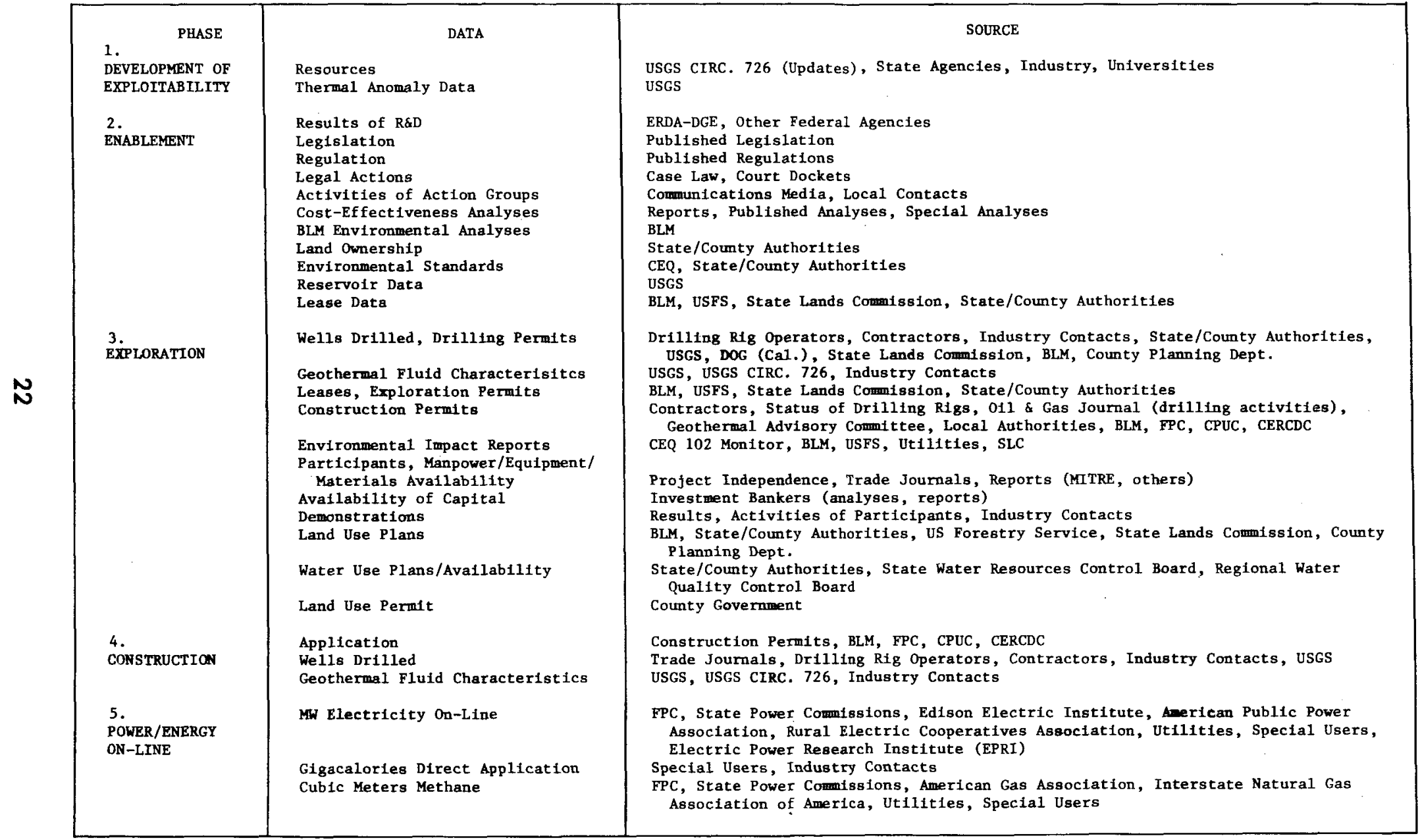


goals are stated--power on line, including direct application of geothermal energy and methane gas.

Phase 5, actual power on line, presents no conceptual problem in relating to national goals.

Phase 4, construction, is readily interpreted as power on line at some definable point, two to three years in the future, with a very high probability of achievement.

Phase 3 resources have much less of a commitment to production development than Phase 4 resources. Indicators can be defined that can be related to national goals at a point 4 to 10 years in the future, but with more uncertainty than Phase 4 indicators.

Phase 2 resources are exploitable, but no commitment to develop these resources exists so that growth potential estimates of power on 1 ine 10 years or more in the future will be made using an economic model for market penetration. In the case of Phase 1 resources, for which the technology to exploit the resource does not exist, growth potential analyses will be based on projections of future exploitability based on $R \& D$.

The proposed indicators will be described in the following paragraphs.

Phase 5: Power on 1 ine will be the total of all electric power from geothermal resources, total direct application of geothermal energy and energy equivalent of methane generated from geopressured resources. 
Phase 4: The indicator proposed for Phase 4 resources is based on the design goal power $\left[E_{c}(t)\right]$ for each project under construction to be brought on line in the year $t$. Summing $E_{c}(t)$ over all projects planned for completion in the same year will yield a projection of national achievements in geothermal resource development, two to three years into the future, with a high confidence level, that can be compared directly with national goals.

Phase 3: The indicator proposed for Phase 3 resources represents the potential for geothermal energy production based on ongoing commercial exploration projects. One part of the indicator will be the estimated geothermal power on line potential $\left[E_{p}(t)\right]$ of the leased land under exploration, which will be modified as exploration defines the characteristics of the reservoir more precisely. Power is postulated to be brought on line in the year $t$, which will depend on the current status of exploration. The second part of the indicator is a multiplying factor $[F]$ which is a measure of the probability that the energy potential of the reservoir will be realized. 
Generically:

$$
F=F(\text { Exploration, Leases, Permits, Environmental) }
$$

where the variables in $F$ are measures of the completion of exploration, lease and permit acquisition, environmental reports and possibly other requirements for a commitment to construction. Intuitively $F=1$ when all requirements for a commitment have been made. At this time the estimate of energy potential is equal to the commitment of the developer, and the resources are promoted to Phase 4.

Al so

$$
0<F<1
$$

during the exploration phase, before the commitment to construction has been made. Normally $F$ would be an increasing function as project success is achieved. However, lack of success could cause a reduction in the value of $F$, even to zero if the project fails and is abandoned.

Then the potential for growth of geothermal energy from resources in Phase 3 could be represented as:

$$
E=F \cdot E_{P}(t)
$$

summed over all projects. The exploration data on which this indicator is based will not be readily available as they will usually be 
held confidential by the developer. Well data from drilling activities on Federal land must be reported to the U.S. Geological Survey but nonetheless remain confidential. A means for obtaining data on drilling operations being performed on state and private lands and for making them available to the monitoring activity, together with data from drilling on Federal lands, remains to be devised.

Phase 2: Resources in Phase 2 are identified resources which are technologically exploitable as a result of success of $R \& D$ activities, are institutionally enabled by virtue of legislative, regulatory and legal actions and are not inhibited by the activities of action groups or by community opposition. Growth of geothermal energy in competition with other sources of energy will be evaluated by exercising an economic model which will estimate market penetration of each type of energy system based on system costs.

Phase 1: Phase 1 resources are known Resources that are not exploitable for technological or institutional reasons. Resources that are projected to be exploitable at identifiable dates in the future (i.e. future Phase 2 resources) as a consequence of the Federal R\&D program 
and expected program milestones, will be evaluated by the market penetration model with current Phase 2 resources.

\subsubsection{Secondary Indicators}

Specific secondary indicators that will be monitored have not been identified at this time.

\subsubsection{Evaluation of Leasing Data}

Estimates will be made of the potential power that could be brought on line on lands currently under lease--known leased acreage and estimated leased acreage where specific details of leases are not known--and on estimated acreage to be leased in the future by currently scheduled lease sales.

Where specific development or construction plans are known these plans will be reflected directly into the analyses. Where specific development plans are not known, estimates of power that could be brought on line will be made based on:

- estimated recoverable heat energy, for lands associated with, or within, known reservoirs, or

- estimate of average acreage required for a 100 MWe power plant and the probability of success in finding a suitable resource on leased land, for lands not associated with a known reservoir.

For further discussion of procedures for evaluating lease data, see Appendix I. 


\subsubsection{Indicators of Federal/ERDA Accomplishments}

Success of the Federal Geothermal Energy Program will be monitored in two ways:

- Achievement of program milestones,

- Assessment of the impact of the Federal program on the achievement of national goals for geothermal energy development.

Important milestones, that have significant impact on the achievement of national goals, e.g., milestones related to pacing items, items on critical paths, etc., will be identified with the Interagency Geothermal Coordinating Council ${ }^{*}$ and will be singled out for special attention.

Primary national goals are specified in terms of electric power on line and quads of direct thermal application as shown in Table I. Although, except for joint-funded demonstrations, the Federal program will not result directly in power on line or in geothermal energy of direct applications, overall success of the Federal program must be measured in terms of the achievement of these national goals.

Success of the Federal geothermal program will therefore be evaluated by the indicators of resource development. Current achievements are measured by Phase 5 indicators of geothermal power on 1 ine, and Phase 3 and 4 indicators will project near-term achievements up to about ten years ahead.

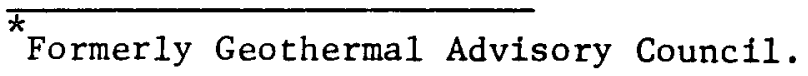


Indicators developed in Phases 3 and 4 are also measures of the magnitude of industry activities in developing geothermal energy. Industry participation will be correlated with resources that have been enabled wholly or in part by Federal R\&D programs, or with resources that have been enabled without Federal R\&D. Other measures of industry response to Federal programs will include:

- uses of the Resources Development Fund;

- application of Federally financed technology, particularly drilling technology, reservoir modeling, instrumentation, equipment, special materials and special techniques; and

- impact of demonstration projects and application of the technology demonstrated.

The correlation of the Federal geothermal energy program with the industry response to the program and with the achievement of national goals for geothermal energy development will permit early diagnosis of incipient problems. It will facilitate identification of the needed remedial action to modify Federal plans and programs to help direct the national effort towards ultimate achievement of national geothermal energy goals.

Phase 1 and Phase 2 indicators of geothermal energy development are estimates of geothermal market penetration based on all the factors that enable geothermal energy for development, including success of current and planned R\&D projects and the resultant impacts on costs, and legislative, regulatory, legal and citizen actions that affect geothermal development. These projections of national achievement in developing geothermal energy (more than ten 
years into the future) will indicate whether the Federal RD\&D

program is setting an adequate foundation for attainment of longrange geothermal energy goals.

\subsection{Information Flow}

The structure of the monitoring system may be understood by considering the sources of information involved. The general flow of information is shown in Figure 3. For the purposes of monitoring the development of geothermal energy, data may be obtained through:

- Regional Operations Research Contractors (or the National Operations Research Contractor),

- R\&D Contractors,

- Other Federal Agencies,

- Other Sources of Information.

\subsubsection{Regional Operations Research Contractors}

Figure 3 indicates that the Regional Operations Research Contractor, who will be referred to herein simply as the "Regional Contractor," will be the principal conduit for information flow from the Region to ERDA. The Regional Contractor will access any and all sources of information within the Region. Where no Regional Contractor has been appointed to a Region, the information can be acquired by the National Operations Research Contractor.

The Regional Contractor should be responsible for planning, promotion, analysis, monitoring and reporting the development and utilization of geothermal energy within the Region. The Regional Contractor, working with local entities, should formulate (or should 


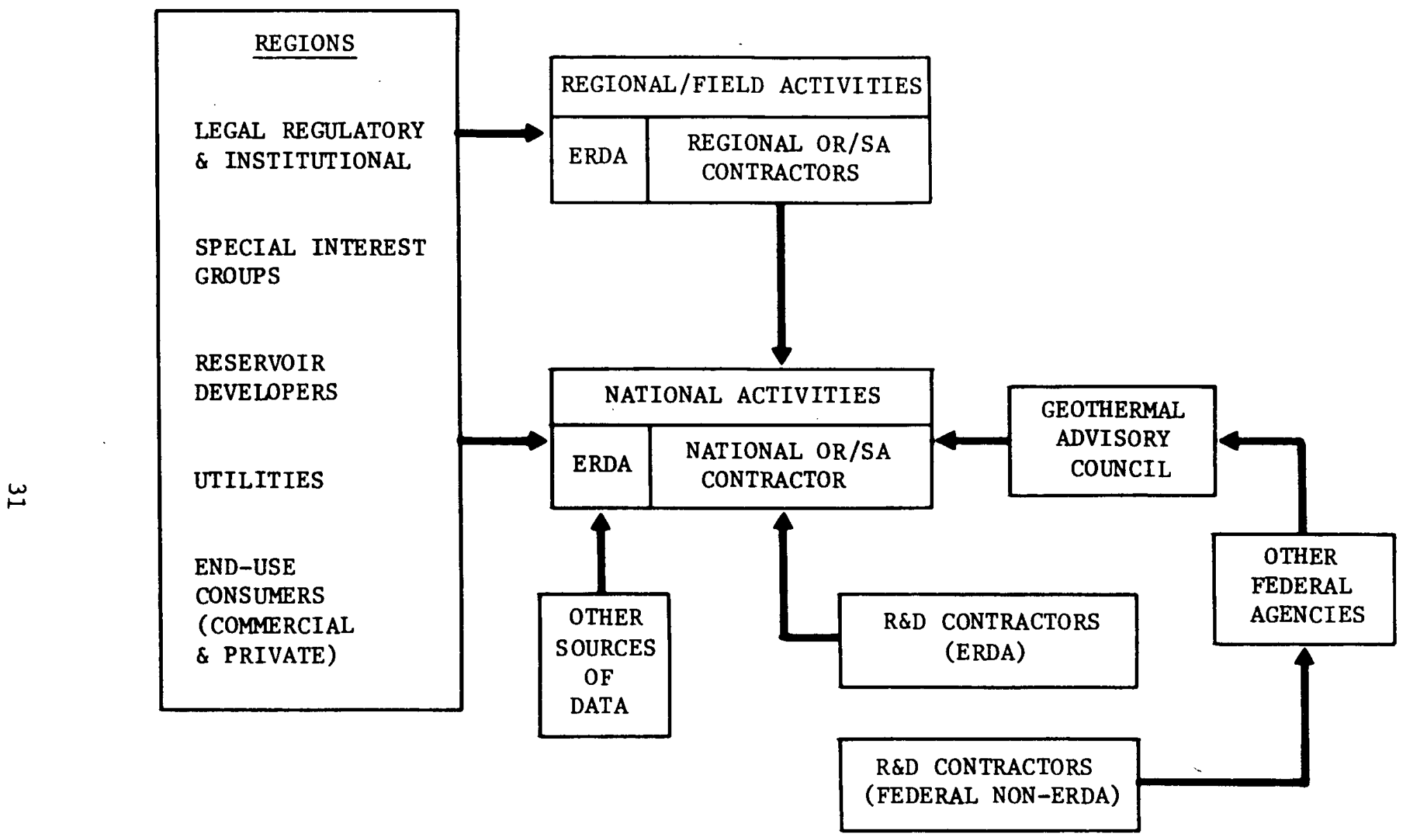

FIGURE 3

DEVELOPMENT OF GEOTHERMAL ENERGY-INFORMATION FLOW 
initiate formulation of) generic plans for development of geothermal plants and should generate scenarios for development of geothermal sites, reservoirs, subregions and regions. Regional scenarios should be aggregated into a national scenario by the National Contractor.

These plans and scenarios will be described in Section 3.

\subsubsection{R\&D Contractors}

Information from the work of Federally-funded R\&D Contractors can be obtained through the normal contract reporting procedures to ERDA or other Federal agency sponsors. These data, together with such additional data as are required for the purposes of monitoring geothermal energy development, should be coordinated at the national leve1.

\subsubsection{Other Federal Agencies}

Various Federal agencies and branches $c$ an be requested directly to provide data under the auspices of the Interagency Geothermal Coordinating Council. The U.S. Geological Survey will be an important source of geothermal information, particularly for basic resource data as in DOI-USGS Circular $726^{[3]}$ and for updated estimates of geothermal energy potential of lands under exploration. Leasing of Federal lands is reported routinely by the Bureau of Land Management--additional detail needed for monitoring can be obtained directly from BLM. Similarly, data on leasing of National Forest lands can be investigated directly with the U.S. Forest Service. 


\subsubsection{Other Sources of Information}

Various information systems, such as GEOTHERM, GeoRef and GRID, contain geothermal energy-related data. GEOTHERM is a computerized file on geothermal fields, geothermal wells and other geothermal topics, developed by the U.S. Geological Survey and operating at the USGS National Center at Reston, Virginia. [5] GeoRef ${ }^{*}$ is a bibliographical data base of the Geological Society of America in Falls Church, Virginia. GRID, ${ }^{* *}$ the "National Geothermal Information Resource," is sponsored by ERDA and developed by the Lawrence Berkeley Laboratory in Berkeley, California. It is a data file on geothermal science and technology including exploration, physical chemistry, utilization, environmental, institutional and reservoir characterization data.

These systems should be reviewed and evaluated for their value in reporting the development of geothermal energy, and all relevant information should be integrated into the reporting system.

\subsection{Supporting Analyses}

\subsubsection{Analyses Developed in Related MITRE/METREK Work}

MITRE/METREK will draw on analyses performed in related tasks in support of the Monitoring function.

Information developed in MITRE Task 1.1[2] will be a starting point for market penetration models to estimate indicators used for Phase 1 and Phase 2 resources.

*Pamphlet "GeoRef" of the Geological Society of America. **Pamphlet "National Geothermal Information Resource" of the Lawrence Berkeley Laboratory. 
The analysis of participants in the National Geothermal Program (MITRE Task 1.2) ${ }^{[6]}$ identifies responsibilities and authorities of Federal Agencies and non-governmental participants and indicates possible sources of data that will be needed to monitor progress of geothermal energy development.

The understanding of the Federal program developed in Task 1.3 will provide MITRE/METREK with basic relationships between Federal program objectives and national geothermal energy development objectives. This will be critical in analyzing indications that emerge from analyses of monitoring data, and will support attempts to correlate indications that the national effort is behind schedule with particular aspects, milestones or objectives of the Federal program.

The cost-benefit analysis approach developed in Task 1.3 will be a key analytical tool. It will support analyses to identify resources that qualify for Phase 2 exploitable resources. It will further provide cost inputs to the market penetration model for Phase 1 and Phase 2 resources and will help to relate these cost inputs to Federal R\&D program milestones.

\subsubsection{Supplementary Analyses}

Additional analyses required in support of the Monitoring function will include:

- Formulation of a model or procedure for estimating power on line for construction projects, 
- Fornulation of a model or procedure for estimating power on line for exploration projects,

- Formulation of a model or procedure that balances the expectations of power on line, resulting from commercial exploration, with constraints based on the availability of participant specialist groups and of equipment, materials, financing and natural resources (particularly water),

- Development of models for estimating power on line (electric and non-electric) that can be expected, and in what time frame, from current Federal, state and private leases, and from scheduled lease sales, and

- Analysis of the interrelationships between measures of progress in the national efforts to develop geothermal energy and achievement of milestones in the Federal geothermal RD\&D program

- Understanding the interrelationships,

- Identifying potential problems,

- Defining possible corrective strategies. 


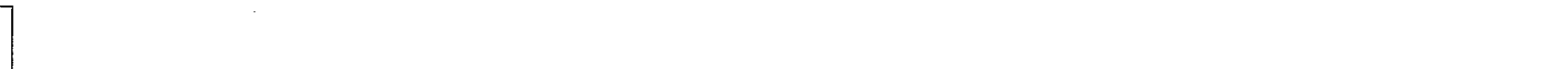




\subsection{GEOTHERMAL DEVELOPMENT PLANS AND SCENARIOS}

MITRE has defined a framework for analysis of geothermal resource development. [7] This has led to the identification of a hierarchy of development plans and scenarios which will serve to formulate and integrate regional and national development programs to achieve national geothermal energy goals (Table I). These plans and scenarios will provide vehicles for specifying and acquiring the basic data that describe the important aspects of geothermal energy development. They will provide a framework for analysis of progress towards achievement of national geothermal energy goals and background descriptions of the geothermal development program for evaluation of the indicators and other measures of progress in geothermal energy development that have been discussed in this report.

The plans and scenarios are briefly summarized below:

1. Geothermal P1ant Development Plan The Geothermal Plant Development Plan (GPDP) is at the lowest and the most detailed level. It will be described in more detail and a sample generic GPDP will be presented.

2. Geothermal Site Development Scenario

A development scenario for a site will incorporate the GPDP for the initial plant development, together with plans for second-generation plants for add-on capacity projected for the future.

3. Geothermal Reservoir Development Scenario

A development scenario for a large reservoir will normally encompass several sites. Small reservoirs may contain only one site and would therefore be represented by a Geothermal Site Development Scenario. 
4. Geothermal Subregion Development Scenario

Subregions, such as Imperial Valley and Long Valley, that encompass more than one reservoir will require a Geothermal Subregion Development Scenario which will be an aggregation of Geothermal Reservoir Development Scenarios.

5. Geothermal Regional Development Scenario All subregions within a region will be aggregated into the Geothermal Regional Development Scenario.

6. Geothermal National Development Scenario Al1 regions will be aggregated into the Geothermal National Development Scenario.

Regional plans and scenarios will be developed by the Regional Contractors. National scenarios will be developed by the National Contractor.

\subsection{Geothermal Plant Development Plan}

The Geothermal Plant Development Plan (GPDP) has been defined as a basic planning element for the development of geothermal energy. [7] A GPDP shows all the major activities and milestones and their interrelationships and provides a detailed schedule which assigns people, capital, materials and natural resources in proper time sequence to all of the tasks required to develop a geothermal plant on a particular site and reservoir.

In the early phases of exploration and resource assessment, when the nature of the geothermal reservoir is not even known for certain, a less detailed "generic" GPDP will be developed. The generic GPDP will be particularized, as far as possible, to the geothermal site being explored. Later in the development of the geothermal plant the GPDP will become "site-specific" and very detailed. However, field 
data, from which a site-specific GPDP will be generated, would be available only for a site under active exploration and exploratory development. The transition from a generic GPDP to a site-specific GPDP will be a continuing process and will normally occur in a series of steps.

\subsubsection{Generic Geothermal Plant Development Plan}

Initially, a generic GPDP will be based on typical values (or estimates) of the parameters. Several different types of generic GPDPs can be formulated based on various possible combinations of :

- Class of reservoir (dry steam, hot brine, warm brine, geopressured),

- Type of implementation (steam turbine, flashed steam, binary cycle, total flow, direct application, etc., as appropriate),

- Land category (Federal, state, private), and

- Leasing policy (competitive, non-competitive).

Based on very limited data, preliminary sample GPDPs have been developed. The data have been acquired from several different sources and these are shown in Table $V$. Where necessary, the data from these sources have been modified and scaled to ensure internal consistency. One sample, for a hydrothermal liquid-dominated, high-temperature resource applied to a flashed-steam electric generating plant, is shown in Figures 4 and 5 and in Table VI. The generic GPDP, approximately ten times more detailed than the preliminary, sample GPDP presented in this paper, should be 
TABLE V

SOURCES OF DATA IN THE SAMPLE GPDP

\begin{tabular}{|c|c|}
\hline ELEMENTS & SOURCES \\
\hline Flowchart & Reference 11 \\
\hline Manpower & Reference 12 \\
\hline $\begin{array}{l}\text { Drill Rigs, Wells } \\
\text { and Feet of Casing }\end{array}$ & References 12,13 and 14 \\
\hline Major Items & $\begin{array}{l}\text { Reference } 12 \text { and MITRE } \\
\text { generated }\end{array}$ \\
\hline Materials & Reference 15 \\
\hline Capital and Costs & MITRE generated \\
\hline
\end{tabular}




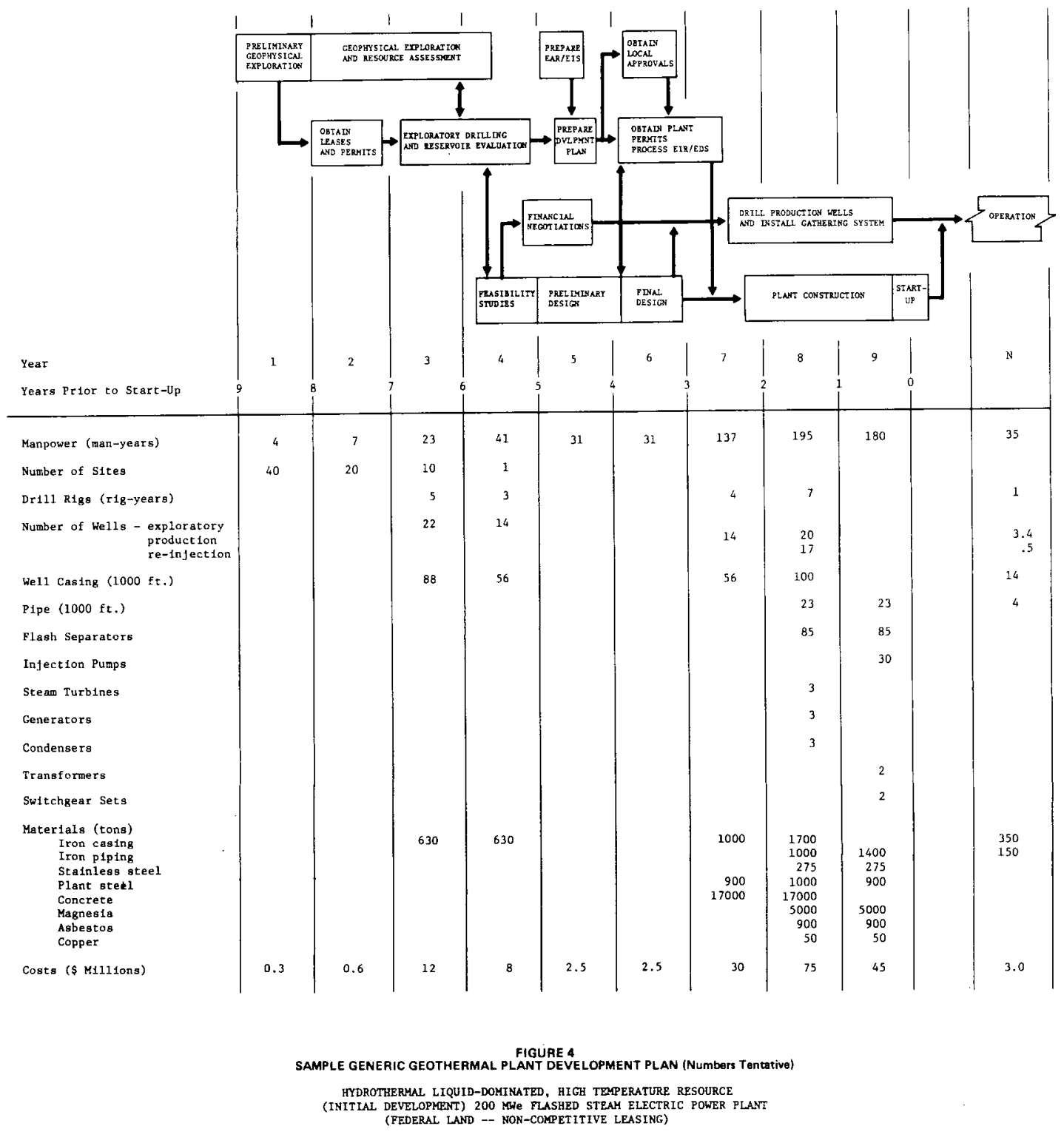




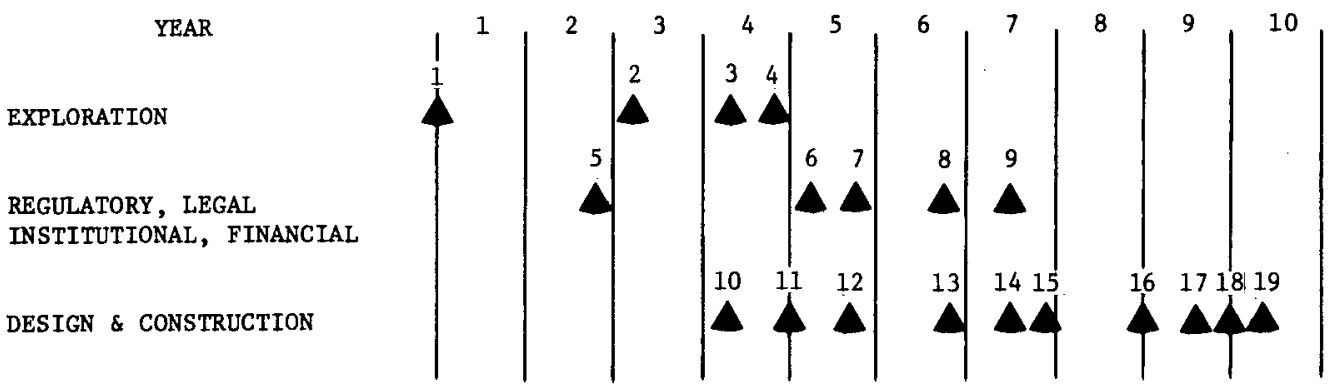

\section{MILESTONES}

EXPLORATION

1. Start preliminary geophysical exploration

2. Start exploratory drilling

3. Complete geophysical exploration and resource assessment

4. Complete exploratory drilling and reservolr evaluations

REGULATORY, LEGAL, INSTITUTIONAL, FINANACIAL

5. Obtain leases and permits

6. Prepare Environmental Analysis Report or Environmental Impact Statement (BLM)

7. Complete financial arrangements

8. Process Environmental Impact Report or Environmental Data Statement (California)

9. Obtain plant permits

DESIGN \& CONSTRUCTION

10. Start feasibility studies

11. Complete feasibility studies, start design

12. Complete Development Plan

13. Conplete design

14. Start drilling production wells

15. Start plant construction

16. Complete drilling production wells

17. Complete Installation of gathering system, complete plant construction

18. Start-up

19. Complete Acceptance Tests

HYDROTHERMAL LIQUID-DOMINATED, HIGH TEMPERATURE RESOURCE (INITIAL DEVELOPMENT) 200 MWe FLASHED STEAM ELECTRIC POWER PLANT (FEDERAL LAND - NON-COMPETITIVE LEASING)

FIGURE 5 SAMPLE GENERIC GEOTHERMAL PLANT DEVELOPMENT PLAN-MILESTONES 
TABLE VI

SAMPLE GENERIC GEOTHERMAL PLANT DEVELOPMENT PLAN - MANPOWER SUMMARY

HYDROTHERMAL LIQUID-DOMINATED, HIGH TEMPERATURE RESOURCE

(INITIAL DEVELOPMENT) 200 MWe FLASHED STEAM ELECTRIC POWER PLANT (FEDERAL LAND - NON-COMPETITIVE LEASING)

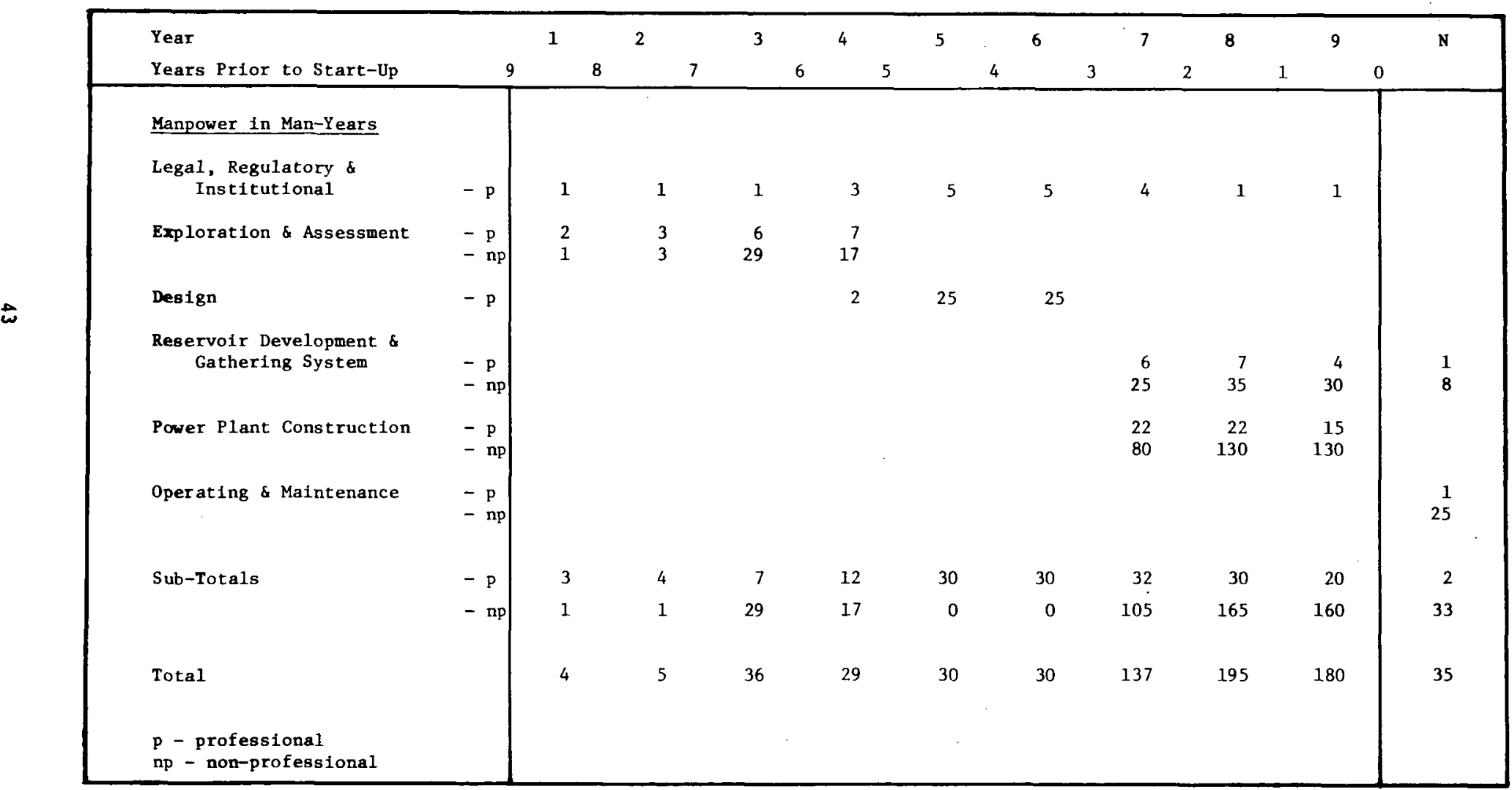


developed by the Regional Contractors. Each box in the sample GPDP would be expanded to a flowchart of interrelated activities and milestones.

3.1.2 Specific Geothermal Plant Development Plan

At the appropriate stage in the development of a geothermal resource, the GPDP will become site-specific. This may be regarded as a stage in the evolution of the GPDP and will usually occur when the characteristics of the geothermal reservoir to be exploited are known with sufficient confidence to permit detailed planning of the development program.

In the initial exploration and development of a new geothermal field, the time for development of a specific GPDP may be after the reservoir has been identified and evaluated. Until that time a generic GPDP may suffice for planning purposes. On the other hand, when additional utilization plants are to be constructed at a site in a known geothermal reservoir, the specific GPDPs may be developed before the work of exploration commences.

The site-specific GPDP should be approximately ten times more detailed than the generic GPDP, i.e., about 100 times more detailed than the sample generic GPDP presented in this paper.

\subsection{Geothermal Site Development Scenario}

When a new geothermal site is to be developed, a Geothermal

Site Development Scenario will be written. This scenario will outline plans for a course of development of the site based on the 
current knowledge and expected nature of the resource. Inevitably there will be a great deal of uncertainty about the Site Development Scenario at first, and it may be appropriate to write alternate scenarios.

The first stage of development will be covered by a GPDP for a first generation geothermal plant. When the development of the first plant has progressed to the production drilling phase, the GPDP will have become site-specific and very detailed and the nature of the resource will be fairly well defined. At this time the choice of alternate site development scenarios can be narrowed down and the scenario can also be made much more site-specific.

\subsection{Geothermal Reservoir Development Scenario}

A development scenario for a large reservoir will usually encompass several geothermal sites. However, until leases have been taken on sites and until exploratory drilling has revealed the nature and extent of the reservoir, the development scenario will be general in nature. As Site Development Scenarios are developed, they will be incorporated in summary form into the Reservoir Development Scenario which will be updated to reflect the new information.

\subsection{Geothermal Subregion Development Scenario}

Development Scenarios will be written for subregions, such as Imperial Valley and Long Valley, that contain more than one reservoir. Subregion Development Scenarios will be aggregations of 
Reservoir Development Scenarios and will be updated periodically as the Reservoir Development Scenarios are updated.

3.5 Geothermal Regional Development Scenario

Development Scenarios for all subregions and reservoirs within a region will be aggregated into a Regional Development Scenario by the Regional Contractor. Regional Development Scenarios should be updated annually.

\subsection{Geothermal National Development Scenario}

Development Scenarios for all regions will be aggregated into a National Development Scenario. National Development Scenarios should be updated annually. 


\subsection{IMPLEMENTATION}

The machinery for acquisition of data in support of the monitoring function has not yet been established. This section describes the requirements for implementation of the monitoring function and then describes a preliminary estimation of monitoring indicators on an ad hoc basis, utilizing available data.

Data relative to development of geothermal resources are very limited. Available data are mostly relative to developments in The Geysers. Very little definitive data are available on exploration and exploitation activities or plans for development in liquid hydrothermal resources.

Data on actual activities and plans are used where they are available. As surrogates for data on exploration and exploitation activities in liquid hydrothermal resources, leasing data are used to estimate upper bounds on possible development of geothermal resources. Current plans or intentions to proceed with this development are, for the most part, lacking or unknown.

\subsection{Implementation Plan}

Implementation of the monitoring function calls for two principal interdependent efforts:

- Formulation and estimation of preliminary indicators.

- Development of the data base. 


\subsubsection{Formulation and Estimation of Preliminary Indicators}

Generic formulations for primary indicators have been proposed in Section 2.5 of this report. Preliminary specific formulations will be developed for primary indicators for Phases 3 and 4. These indicators must be such that they $c$ an be estimated from data that is likely to be available and they must yield results that are "reasonable." Criteria of "reasonableness" are to be defined.

Primary indicators for Phases 1 and 2 will be computed using an economic model for market penetration based on costs of geothermal energy and competing energy systems. The method is to be defined.

Secondary indicators will be specified and formulations defined. In many cases the secondary indicators, or some derived quantity, will be a direct data input to the computation of primary indicators. In other cases the secondary indicators measure enabling factors that are needed for development of geothermal resources.

The formulations for indicators that are developed will be tested in an analysis of national program status in which initial values of the indicators will be estimated. Refinement and reformulation of indicators will be a continuing task.

\subsubsection{Development of the Data Base}

Development of the data base is a critical task for the following reasons:

- The whole monitoring function depends on the data.

- Acquiring the data will be a time consuming activity of considerable magnitude. 
- The quality of monitoring will be, in large measure, dependent on the quality and completeness of the data. Much of the data gathering activity will be directed to determine just what data can be acquired. Certain data are known not to be currently available--the effort will be to ensure availability at some time in the future if possible.

4.1.2.1 Data Specifications. Preliminary specifications of data requirements have been given in Table IV. Detailed specifications will be developed including:

- Data schedules which will guide Regional Contractors and will specify data to be made available to the National Contractor through the Regional Contractor.

- Data required from Federal Agencies. These will include leasing data from the Bureau of Land Management and the U.S. Forest Service, and updated and detailed reservoir data from the U.S. Geological Survey.

- Significant Federal RD\&D program milestones. These will be defined under the auspices of the Interagency Geothermal Coordinating Council.

The data specifications will prescribe the level of detail required and possible alternates where there may be doubt that the data can be obtained.

4.1.2.2 Data Acquisition. A preliminary tabulation of possible sources of data has been given in Table IV. In close coordination with Regional Contractors, the specification of data sources will be be refined and updated. In many cases the sources, or even the availbility, of some data cannot be determined with certainty until the attempt is made to acquire them. For example, specific map locations and areal extension of reservoirs are probably not currently available 
and a special requirement will have to be made to obtain these data in the future, possibly when DOI-USGS Circular $726^{[3]}$ is updated. Some of the detailed data required on leases--again on precise map locations--are not normally published and would have to be obtained from regional offices of BLM. As such this should be a task for the Regional Contractor.

Preliminary data should be acquired by May 1, 1977, for input to a first-pass analysis of national progress in geothermal energy development. The preliminary evaluation of indicators will then be completed for inclusion in DGE reports (PAD, Program Plan).

\subsubsection{Data Base Implementation. Concurrent with the acqui-} sition of preliminary data, a computerized data base should be designed and implementation commenced. The data base would feature:

- A Resources File

- Reservoirs

- Known Geothermal Resource Areas

- Potential Geothermal Resource Areas

- An Activities File

$\bullet$ RD\&D Projects and Tasks

- Commercial Exploration and Development Projects

- Institutional and Legal Activities

- Past, Current and Future Activities

- Storage and Retrieval

- Preparation of Special Displays, Inputs to Documents

- Data Processing and Analyses.

The monitor data base should be integrated with the DGE Management Information System, Project Milestone Display System and other 
DGE data bases under a common data base management system. The development of the computerized data base should be on a schedule consistent with the orderly, long-term development of the monitoring function. In the near term, while analysis procedures are being developed, and while preliminary data are being acquired, manual, computer-assisted processing will be more appropriate. A more detailed discussion of DGE data base requirements is presented in Reference 13.

\subsection{Preliminary Implementation}

This section describes the data and lists data sources that have been used to make preliminary estimates of indicators of progress in geothermal energy development.

\subsubsection{Description of Data Used}

Phase 5: Resources Producing Power On Line

The principal applications of geothermal power on line in the United States are the electric generating plants at The Geysers [4] (502 MWe) and heating systems in Klamath Falis, Oregon [14] (5.6 MWt) and Boise, Idaho [15] (9.2 MWt).

Phase 4: Resources Committed to or Under Construction Current construction of geothermal power plants is mostly at The Geysers. Pacific Gas and Electric* (PG\&E) has four new plants (Units 12, 13, 14, 15) under

\footnotetext{
*

From Reference 4 and by direct communication with Pacific Gas and Electric (PG\&E).
} 
construction and two in the design phase (Units 16, 17). Northern California Power Agency (NCPA) has four 55 MWe plants planned to go on line in 1979, 1980, 1981, and 1982. [4] Other plants in design or under construction include the thermal loop flashed-to-binary test facility at Niland, California which, if successful, will lead to a 10 MWe pilot plant in FY 80; and the thermal loop integrated energy conversion facility at Raft River, Idaho. [16] These projects are summarized in Table VII. Some production-type drilling is underway in the following reservoirs ${ }^{[2]}$ :

Salton Sea, California

Heber, California

East Mesa, California

Brawley, California

Valles Caldera, New Mexico

No known committments have been made to construct power plants but the above reservoirs are considered to have the highest potential for early development. [2] San Diego Gas and Electric has pursued plans to construct a 50 MWe Demonstration Plant at Heber with a schedule to commence operation in 1980. [17] This and other activities in the above reservoirs are 
TABLE VII

GEOTHERMAL ENERGY PLANTS IN DESIGN OR UNDER CONSTRUCTION $\left(\mathrm{MW}_{\mathrm{e}}\right)$

\begin{tabular}{|l|cccc|c|}
\hline & \multicolumn{3}{|c|}{ On-Line } & \\
\hline & 1978 & 1979 & 1980 & 1981 & Status \\
PG\&E/Geysers & 271 & 135 & & & Under construction \\
PG\&E/Geysers & & & 220 & & Design phase \\
Raft River, Idaho \\
Niland, California
\end{tabular}


regarded as being in the late exploration, preconstruction phase.

Phase 3: Resources Under Commercial Exploration

Very little data on current exploration activities are available to MITRE/METREK at this time. As discussed in Section 2.4, data on the results of exploration activities will not be readily available and acquisition of these data is going to be a timeconsuming process.

It is known that Union Oil Company, operator of the steam supply system at The Geysers, has explored and drilled wells to nearly double the present generating capacity of $502 \mathrm{MWe}{ }^{[18]}$ The additional steam capacity is probably sufficient to supply new electric generating plants scheduled for completion through 1979.

Some exploratory drilling activity is underway at the following reservoirs: [2]

Chand ler, Arizona

Coso H.S., California

Long Valley, California

Surprise Valley, California

Mountain Home, Idaho

Beowawe, Nevada 


$$
\begin{aligned}
& \text { Brady's H.S., Nevada } \\
& \text { Steamboat Springs, Nevada } \\
& \text { Roosevelt (McKean) H.S., Utah } \\
& \text { Bingham City, Utah }
\end{aligned}
$$

Phase 2: Exploitable (Undeveloped) Resources

The principal method for evaluating Phase 2 resources is by means of an economic model of market penetration. At the time of writing, MITRE/METREK's first effort to estimate market penetration is underway but results are not yet available.

Phase 1: Known Resources

The method for evaluation of Phase 1 resources is to apply a market penetration model to Phase 1 resources that are projected to become Exploitable Resources (Phase 2) in the future. These resources are then analyzed with Phase 2 resources. The results of these analyses were not available at the time of writing .

Leasing Data

- "Geothermal Lease Sale Summary," May 31, 1976[19]

- "Noncompetitive Geothermal Leasing, Summary Status Report," May 31, 1976[20] 
- Private leasing

Union Oil of California/Magma Power Company/Thermal Power Company - joint holdings in The Geysers of 15,000 acres (1973).* 3,500 acres in use for current on-line power generation of $502 \mathrm{MWe}{ }^{* *}$ Estimated other private leasing, 3,000,000 - 10,000,000 acres. [8]

- California State Leasing

Tabulation of California state lands under lease and under prospecting permits as of December 15, 1975. [4] (Source: State Lands Commission)

- Future Lease Sales

Tentative schedule of KGRA lease sales from April 20, 1976 through FY 1977 and FY 1978. [22]

\subsubsection{Analysis of Data}

The data described in Section 4.2.1 have been analyzed to estimate potential geothermal power on line through 1990.

Except for The Geysers, there is little definitive information on construction and exploration activities or on plans for future geothermal development. Current plans of electric utilities for development of geothermal energy are summarized in Table VIII. Current construction (Table VII) plus current plans for future development (Table VIII) in The Geysers through 1990, are estimated to require just about all the known leased private, state and Federal 1 and in The Geysers. Information on private land leased in The

\footnotetext{
$\star_{\text {Reference } 21, \text { p. } 146 .}$ $* *$

Private communication with John P. Finney, Pacific Gas and Electric.
} 
TABLE VIII

ELECTRIC UTILITIES--PLANS FOR GEOTHERMAL POWER DEVELOPMENT

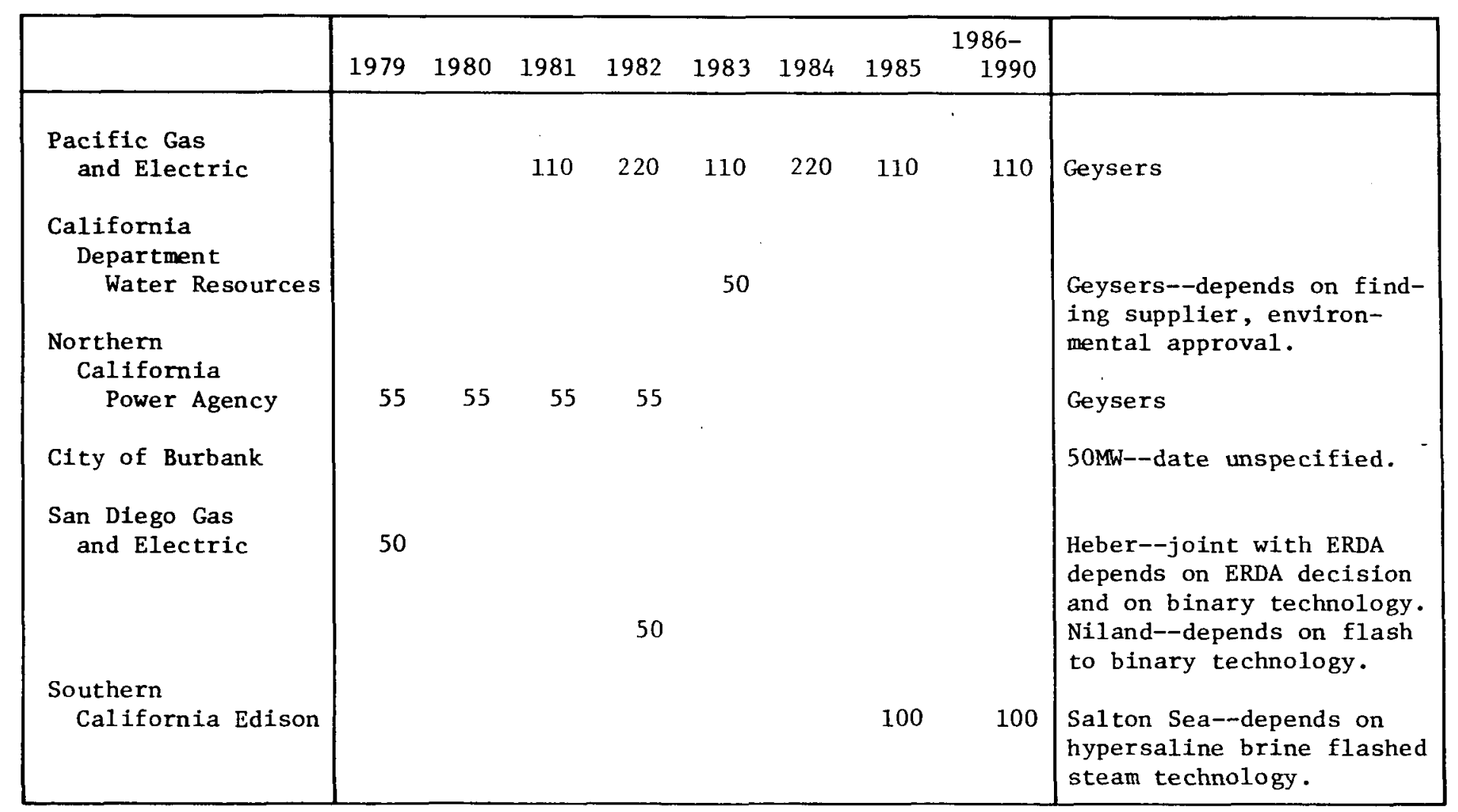


Geysers is dated 1973--it is possible that additional private leases have been sold since then.

Analysis of the potential for geothermal development of 1iquiddominated hydrothermal reservoirs is based primarily on leasing data. Analysis of leasing data can provide estimates of an upper bound to the possible energy on line from those leased lands.

The evaluation of potential power on line from leased land can be constrained in time by two factors:

1. The time line for initial development of a liquid dominated hydrothermal reservoir, from preliminary geophysical exploration through power on line, is about 9 to 10 years *

2. Under current 1 aw Federal leases will be terminated unless drilling is commenced within 10 years and power is being generated in commercial quantities within 15 years of lease date.

Estimates of the geothermal power potential of leases have been postulated to come on line in time frames commensurate with the known status of geothermal development as described in Section 4.2.1 and Reference 2, and subject to the Constraints 1 and 2 above.

In the Heber reservoir, plans for a 50 MWe demonstration plant have been pursued by San Diego Gas and Electric, as previously stated. Realistically this plant would not be on line before 1981 . For leased 1 and in the Salton Sea, Heber, East Mesa, Brawley and Valles Caldera, where the status is assumed to be pre-construction exploration, the potential power production has been postulated to be

* See Section 3 
brought on line starting in 1981 with the Heber demonstration, and continuing through 1987 at an assumed uniform annual rate.

In the reservoirs where some exploratory drilling activity is occurring--Chandler, Coso H.S., etc. ${ }^{*}-$ the power potential of the leased land has been postulated to come on line in the time frame 1983-1990. For other leases, including state and private leases for which the reservoir is not known, the potential power has been postulated to come on line over a five-year period in the time frame of 1986-1990.

The leasing data have been analyzed in accordance with the methods proposed in Appendix I.

A summary of the analyses of geothermal development of power on line, from the available data on current and future lease sales, is presented in Table IX.

\subsubsection{Estimates of Power On Line}

The estimates of power on line are summarized by year and by phase of development in Table $X$.

\footnotetext{
* See Section 4.2.1.
} 
TABLE IX

ANNUAL NEW POWER-ON-LINE POTENTIAL OF GEOTHERMAL LEASES (MW ${ }_{e}$ )

\begin{tabular}{|c|c|c|c|c|c|c|c|c|c|c|c|c|c|c|c|}
\hline & 1976 & 1977 & 1978 & 1979 & 1980 & 1981 & 1982 & 1983 & 1984 & 1.985 & 1986 & 1987 & 1988 & 1989 & 1990 \\
\hline \multicolumn{16}{|l|}{ GEYSERS } \\
\hline Construction & & & 271 & 135 & 220 & & & & & & & & & & \\
\hline Planned Expansion & & & & 55 & 55 & 165 & 275 & 160 & 220 & 110 & \multicolumn{5}{|c|}{110} \\
\hline Total Geysers & & & 271 & 190 & 275 & 165 & 275 & 160 & 220 & 110 & & & 110 & & \\
\hline \multicolumn{16}{|l|}{ LIQUID HYDROTHERMAL } \\
\hline Construction & & & & & 10 & 10 & & & & & & & & & \\
\hline Pre-Construction & & & & & & 50 & 50 & 50 & 50 & 50 & 50 & 40 & & & \\
\hline Exploration & & & & & & & & 110 & 110 & 110 & 110 & 110 & 110 & 110 & 110 \\
\hline Other Federal Leases & & & & & & & & & & & 570 & 570 & 570 & 560 & 560 \\
\hline Future Federal Leases & & & & & & & & & & & & 20 & 90 & 130 & 150 \\
\hline $\begin{array}{l}\text { California State } \\
\text { Leases }\end{array}$ & & & & & & & & & & & 20 & 20 & 20 & 20 & 20 \\
\hline Private Leases & & & & & & & & & & & 600 & 600 & 600 & 600 & 600 \\
\hline Total Liquid & & & & & 10 & 60 & 50 & 160 & 160 & 160 & 1350 & 1360 & 1390 & 1420 & 1440 \\
\hline
\end{tabular}


TABLE $\mathrm{X}$

POTENTIAL GEOTHERMAL POWER ON LINE ( $\mathrm{MW}_{\mathrm{e}}$ )

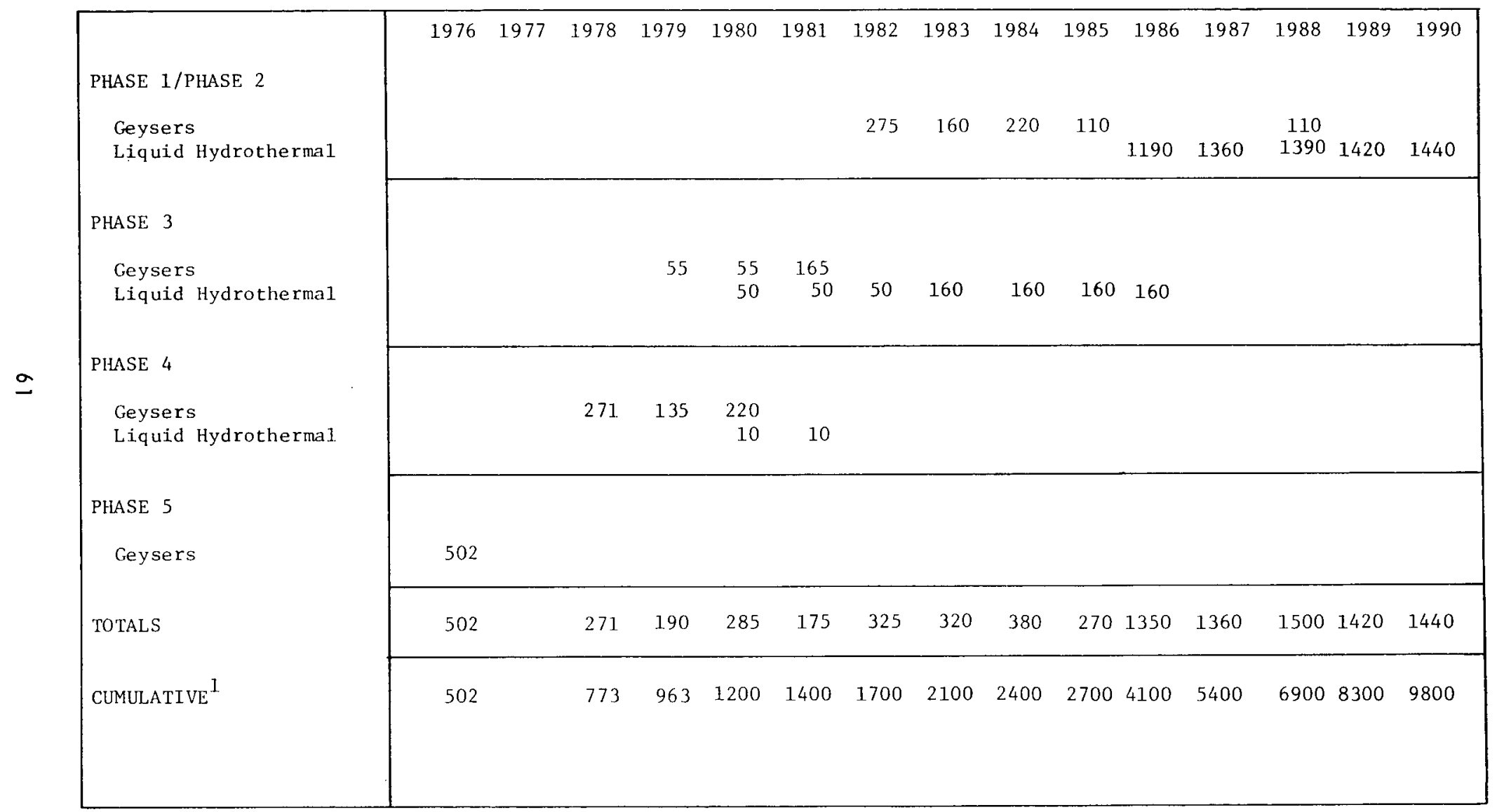

${ }^{1}$ Rounded to nearest $100 \mathrm{MW}$ e from 1980. 


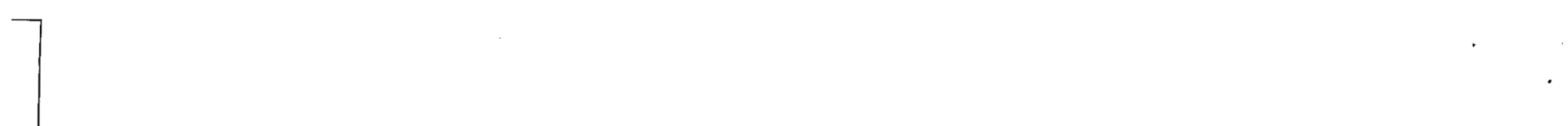




\subsection{SUMMARY AND CONCLUSIONS}

The concept of a Monitoring System for tracking and evaluating progress of geothermal energy development in the United States has been described. The system is designed to track the overall achievements of national geothermal energy development efforts and to evaluate projected achievement against national goals with sufficient lead time to enable timely corrective action to be taken when there are indications of potential slippage.

The principal indicators of geothermal development have been proposed in terms of "power on line" which can be related directly to national goals for geothermal energy development. The health of the geothermal energy program will be monitored in terms of indicators of power on 1 ine, which $c$ an be projected against future goals, on the basis of estimated geothermal energy resources at several well-defined phases of development maturity. Short, medium and long-range indicators will be developed to give lead time of up to 15 years and more on indications that the national geothermal energy development efforts may be behind schedule.

The Federal Geothermal Energy Program will be closely correlated with the national effort so that corrective action can be identified to help bring the national effort back on schedule.

A preliminary estimation of monitoring indicators has been made on an ad hoc basis. Some data on development activities in The Geysers are available. Otherwise data have generally been unavailable. 
In 1 ieu of the required data on development activities in liquid hydrothermal resources, leasing data have been used as surrogates. The analysis of available data must therefore be regarded as essentially illustrative and not definitive. Notwithstanding the limitations on the analyses, some conclusions can be drawn.

- The estimates of new power on line each year from 19861990 are about an order of magnitude greater than new power on line each year in the years prior to 1986. The distrubution of these estimates is subject to two constraints:

1. The time line to bring new power on line from liquid hydrothermal resources is about 10 years from preliminary exploration. Reasonable assumptions have been made regarding how much earlier some of the estimated power from these resources could be brought on line; however it must be concluded that most of the resources on leased land, resources on which there has been no active development activity, will not be brought on line before 1986.

2. The Geothermal Steam Act of 1970 requires that active development of a Federal lease be undertaken within 10 years of lease date and that power should be generated in commercial quantities within 15 years. For the purpose of estimating upper bounds on resource development potential, this constraint has been assumed to imply that, where a suitable resource is discovered on leased land, the total resource on the lease will be developed within the 15-year time period.

- About half of the new power on line during the period 1986-1990 is from Federal leases which are subject to the constraint in (2) above. The other half is from private leases which may not be subject to the same constraint but is, however, subject to considerable uncertainty.

- The analyses have been based on leasing data alone and it has been assumed that leased lands will be developed on a time scale consistent with requirements of the law regarding development of Federal leases. The conclusion that has been reached--namely that annual new power on line increments will jump an order of magnitude after 1985--may not be 
supported by other development factors. A possible implication is that a proportion of leases may be allowed to lapse without development, or that the probabllity of success in developing a lease may be lower than assumed.

Certain tasks require early attention and definition:

- Development of detailed data specifications,

- Development, with the National and Regional Contractors, of a specification for machinery to acquire data,

- Selection of a data management system,

- Specification and preliminary implementation of a data base in a form suitable for automated data management. 


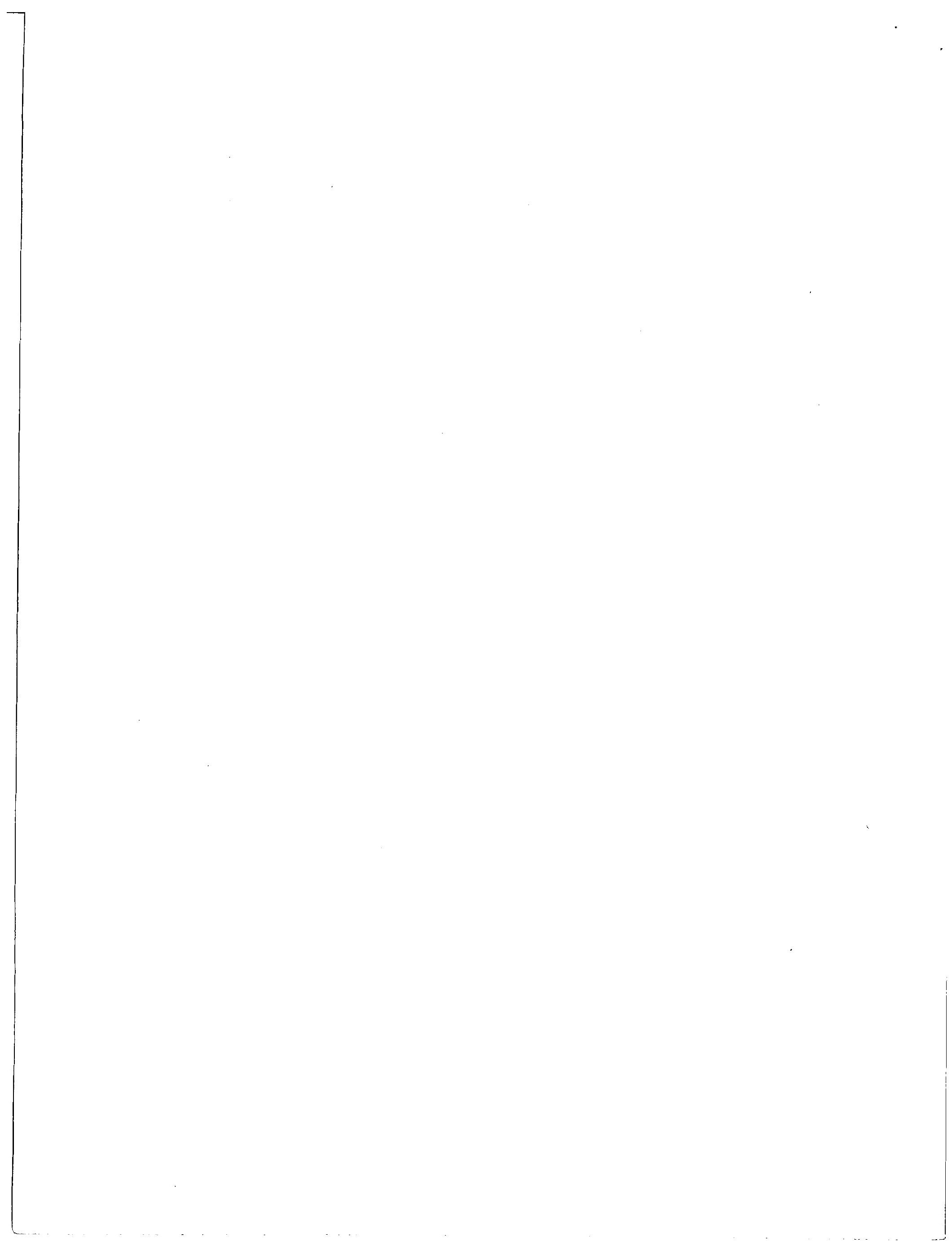


REFERENCES

1. U.S. Energy Reseach and Develpoment Administration (ERDA), "Geothermal Energy Research, Development and Demonstration Program," ERDA-86, October, 1975.

2. John G. Leigh, Susan Pond, Ranvir K. Trehan, Felicia Williams, "Analys is of Geothermal Energy Development Scenarios," The MITRE Corporation, METREK Division, MTR-7220, November, 1976.

3. D.E. White and D.L. Williams, Editors, "Assessment of Geothermal Resources of the United States - 1975," U.S. Department of the Interior, Geological Survey Circular 726, 1975.

4. "Report on the Status of Development of Geothermal Energy Resources in California," Jet Propulsion Laboratory, Report No. 5040-25, March 31, 1976.

5. Allen L. Clark, James C. Calkins, E. Tongiorgi and E. Stefanelli, "A Report on the International Geothermal Information Exchange Program," Unpublished Report of USGS, privately communicated by James A. Calkins, March 29, 1976.

6. H. W. Joy, "Participants in the National Geothermal Program," The MITRE Corporation, METREK Division, MTR-7243, November, 1976.

7. Arnold Cohen, Steven N. Goldstein, John G. Leigh, "Framework for the Analysis of Regional and National Geothermal Resource Development," The MITRE Corporation, METREK Dvision, WP-11411, February 17, 1976.

8. "Program Definition for the Development of Geothermal Energy," Jet Propulsion Laboratory, Report No. 5040-6, August 29, 1975.

9. Project Independence Blueprint. Final Task Force Report-Geothermal Energy, November 1974.

10. The Futures Group, "A Technology Assessment of Geothermal Energy Resource Development," National Science Foundation, Report NSF-RA-X-75-011, April 15, 1975.

11. Subcommittee for Resource Exploration and Assessment of the Geothermal Industry Liaison Group on the Task Force Report, Geothermal Energy and on the USGS Geothermal Research Program, Estimate submitted by William Glass, February 28, 1975. 
REFERENCES (Continued)

12. W. Wheelock, Private communication, The MITRE Corporation, METREK Division, February 25, 1976.

13. Adrienne Kleiboemer, "DGE Data Base Requirements," The MITRE Corporation, METREK Division, WP-11928, November 19, 1976.

14. John W. Lund, "Geology and Energy Utilization of the Klamath Falls Known Geothermal Resource Area," Geothermal World 1975/76.

15. J. H. Howard, "Principal Conclusions of the Committee on the Challenges of Modern Society. Non-Electric Applications Project," J.H. Howard, Lawrence Livermore Laboratory; paper presented at the Second United Nations Conference on Geothermal Resources, Paris, France, June 1975. UCRL-76408.

16. "Program Approval Document, Fiscal Year 1976 and Transition Quarter, Geothermal Energy Development." U.S. Energy Research and Development Administration (ERDA), Solar, Geothermal and Advanced Energy Systems Development, June 1976.

17. SDG\&E Pre-Proposal to ERDA, "Construction of a 50 MW Demonstration Geothermal Power Plant." July 9, 1976.

18. B. Greider, "Status of Economics and Financing Geothermal Energy Power Production," Chevron Oil Company, May 1975.

19. "Geothermal Lease Sale Summary," May 31, 1976. Tabulation of KGRA lease sales by the Bureau of Land Management from January 22, 1974, to May 18, 1976 (Not Pub1ished).

20. "Noncompetitive Geothermal Leasing," Summary Status Report, May $31,1976$.

21. Paul Kruger and Carel Otte, "Geothermal Energy - Resources, Production, Stimulation," Stanford University Press.

22. "Tentative Geothermal Lease Schedules," Federal Register, Vol. 41, No. 78 - Wednesday, April 21, 1976, p. 16668.

23. U.S. Geological Survey, Conservation Division, "Geothermal Land Classification Maps." 
APPENDIX I

ANALYSIS OF LEASING DATA

For the purposes of analysis, leases may be categorized as follows:

1. Leases for 1 ands under active commercial development-exploration and exploitation.

2. Leases for land not yet under active commercial development:

- Leases for lands within hydrothermal reservoirs identified and described in DOI-USGS Circular 726, or reservoirs for which specific physical data are otherwise available,

- Leases for lands outside identified hydrothermal reservoirs but within areas associated geothermally with identified reservoirs (KGRAs and areas "valuable prospectively for geothermal resources"), ${ }^{*}$ and

- Leases for lands not associated with identified hydrothermal reservoirs.

3. Leases that are scheduled to be sold in the future by BLM, USFS and state agencies.

Leases Under Active Commercial Development

Development activities are known to be going on in certain reser-

voirs. Estimates of power from known leases in these reservoirs will

be postulated to come on line in time frames commensurate with the

status of development in those reservoirs. Where specific construction

plans or development plans are known, particularly in The Geysers,

these plans will be reflected directly into the analyses. Where

${ }^{*}$ As defined by U.S. Geological Survey. [23] 
specific development plans are not known, and this applies to most of the liquid hydrothermal resources, estimates of power that can be brought on line will be made using the procedures described below, for leases not under active development. Leases Not Under Active Development

Two procedures are proposed for analyzing leases for lands not yet under active commercial geothermal development. One procedure would be used for lands within or associated with an identified hydrothermal reservoir; the other procedure would be used on lands not associated with an identified hydrothermal reservoir. Lands Associated with an Identified Hydrothermal Reservoir From the physical characteristics of the reservoir, such as those given in DOI Circular $726,{ }^{[3]}$ the stored energy per acre can be derived. Recovery factors (fraction of stored energy recoverable as electrical energy) ${ }^{*}$ are as follows:

- 1 iquid-dominated, $150^{\circ} \mathrm{C}-200^{\circ} \mathrm{C}--.02$

- liquid-dominated, $200^{\circ} \mathrm{C}-250^{\circ} \mathrm{C}--.025$

- vapor-dominated ( 5 percent 1 iquid resource) --- .019

Using the factor--

$$
10^{18} \text { calories }=3880 \text { MWe for } 30 \text { years }
$$

the stored energy can be converted to potential MWe on line per acre for 30 years $(M)$.

\footnotetext{
$\bar{*}$ From DOI-USGS Circular 726, ${ }^{[3]}$ p. 107.
} 
If the leased land is within the identified reservoir the on-line potential of the leased area (A) is given by:

Potential power on line $=M \cdot A$ MWe

If part or all of the leased land is not within the identified reservoir, it may be assumed that the actual reservoir extends beyond the boundaries of the identified reservoir, with the same temperature and the same value of stored energy per acre, but with a lower probability that the resource will be found in any particular location.

It is possible that the per-acre price paid for the lease may be used to estimate a probability factor. One way to do this could be as follows:

A nominal price per acre $\left(\mathrm{P}_{\text {nom }}\right)$ is defined as a function of the temperature of the resource. A possible relation of $p_{\text {nom }}$ against temperature for liquid-dominated hydrothermal resources is shown in Figure 6 . The nominal price per acre may be effectively the price that should be paid for the lease if the lands are within the reservoir. Then a factor f can be defined such as:

$$
f=.04+.96 \frac{\mathrm{P}_{\text {av }}}{\mathrm{P}_{\mathrm{nom}}}
$$

where $P_{a v}$ is the average per acre price paid for the lease. The factor $f$ has the property that it does not fall below .04 for very low values of $\mathrm{p}_{\mathrm{av}}$. This is equivalent to a 


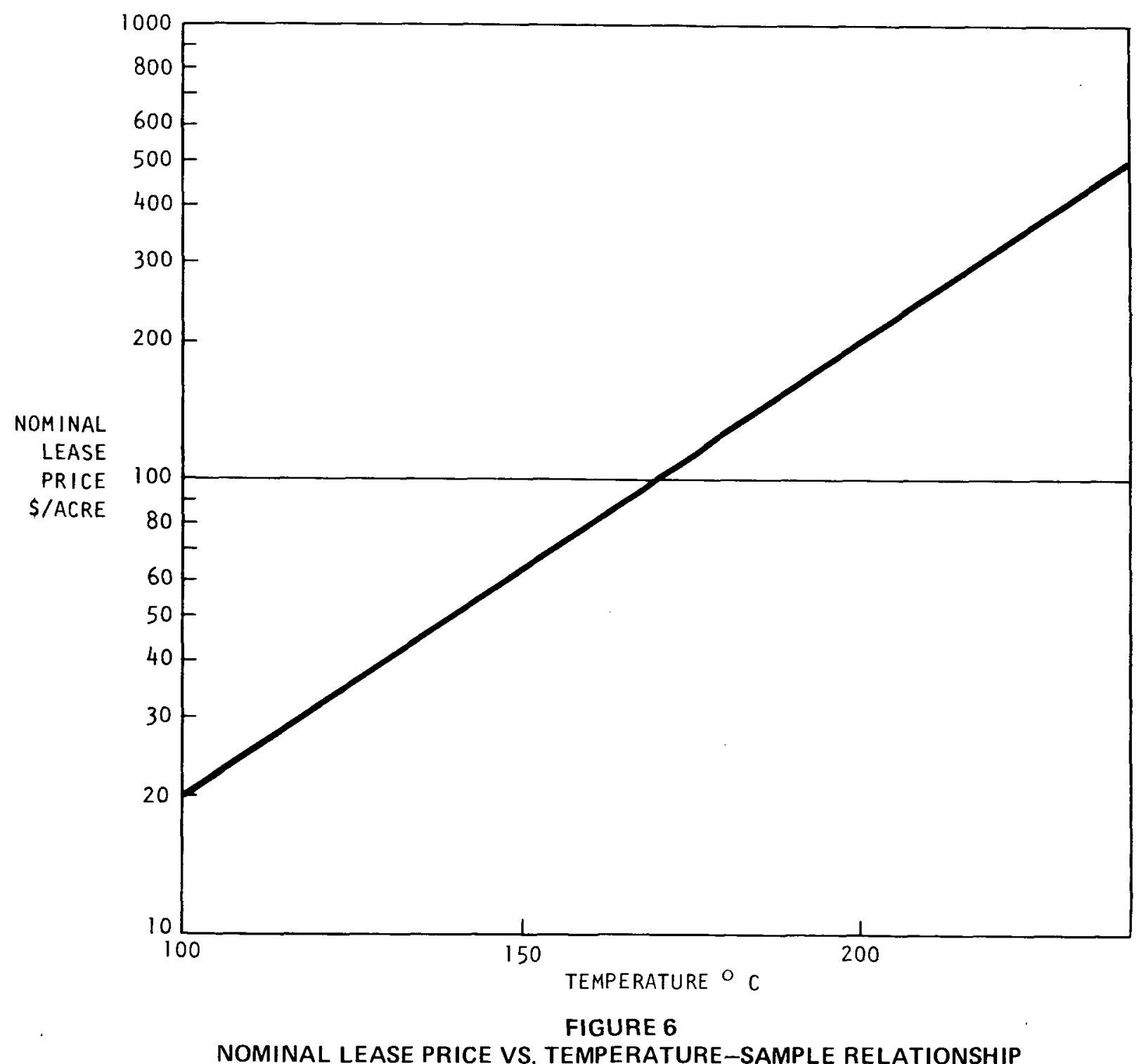


success ratio of $1: 25$ which has been proposed ${ }^{[2]}$, based on the published opinons of several well known authorities on geothermal energy for geothermal leases on lands for which no geothermal resource has been identified. Also $f=1$ when $\mathrm{p}_{\mathrm{av}}=\mathrm{p}_{\text {nom }}$. Intuitively, one also feels that value of the lease should vary linearly with the probability of success. For vapor-dominated resources, a higher value of $\mathrm{p}_{\text {nom }}$ may be chosen, since the technology has been proved. Thus for The Geysers recent prices paid for leases indicate that a value of $P_{\text {nom }}=\$ 3000$ may be appropriate. Lands Not Associated with an Identified Hydrothermal Reservoir Where there is no indication of the nature of the resources that may be associated with individual leases a simplified approach may be used. It may be assumed that there is an average probability of success ( $f$ ) in finding a suitable resource in the leased 1 and, and that a certain acreage of 1 and $\left(\mathrm{L}_{a}\right)$ with this resource is required to provide the energy for an electrical generating plant of a given size (100 MWe for example). Then the potential for MWe on line of a total of leased acreage (A) would be

$$
\frac{100 \mathrm{f} \cdot \mathrm{A}}{\mathrm{L}} \mathrm{MWE}
$$

As stated above, based on the published opinions of several we 11 known authorities on geothermal energy, a success ratio of $1: 25$ ( $f=.04)$ has been adopted for lands not associated with an 
identified resource. [2] For KGRA lands however, the fact that there has been competitive interest, even though USGS has not proposed an identified resource for those lands, is an indication that the probabjlity of success may be higher. Accordingly it has been assumed that $\mathrm{f}=.1$ for these KGRA 1 ands not associated with an identified resource. Scheduled Lease Sales

A schedule for future KGRA lease sale offerings is published periodically in the Federal Register. [22] The schedule gives date (or month) of sale and the names of the KGRAs. Each sale will be in the range $10,000-30,000$ acres, although these limits are not firm. The average acreage offered for sale may be taken to be about 20,000 acres. $*$ Each sale comprises a number of individual leases, each of which is $1 \mathrm{imited}$ by 1 aw to 2560 acres.

An estimate must be made of leases sold from leases offered for sale. Between January 1, 1974 and May 31, 1976, 653,328 acres of Federal KGRA 1 and was offered for sale by BLM; 302,378 acres of land or 46 percent was actually leased. [19] However, the ratjo of lease area sold to lease area offered for sale appears to have been declining during this period, as indicated in Table XI, although the trend is not clear cut.

The declining trend may be in part an indication that the more interesting lands were offered for sale first; it may also indicate that the potential buyers became financially committed and have been

\footnotetext{
The average offering from January 1974 through May 18, 1976 was
} 21,700 acres. [19] 
TABLE XI

BUREAU OF LAND MANAGEMENT SALES OF KGRA LEASES [7]

\begin{tabular}{|c|c|c|c|}
\hline \multirow{2}{*}{ Period } & Leases Offered & \multicolumn{2}{|c|}{ Bids Accepted } \\
\cline { 2 - 4 } & Acres & \multicolumn{2}{|c|}{ Acres } \\
\hline $1 / 22 / 74-12 / 18 / 74$ & & 71,452 & 64 \\
$12 / 28 / 74-5 / 22 / 75$ & 111,859 & 64,267 & 58 \\
$5 / 29 / 75-6 / 19 / 75$ & 110,489 & 33,024 & 33 \\
$6 / 23 / 75-6 / 31 / 75$ & 100,587 & 33,305 & 28 \\
$9 / 23 / 75-2 / 3 / 76$ & 117,722 & 72,673 & 62 \\
$3 / 3 / 76-5 / 18 / 76$ & 116,894 & 27,657 & 29 \\
\hline $1 / 22 / 74-5 / 18 / 76$ & 94,205 & 302,378 & 46 \\
\hline
\end{tabular}


unable to commit themselves heavily to additional purchases. The potential of future sales offerings should therefore be evaluated with caution.

Future lease sales will be analyzed to improve the trend 1 ine. The recent trend should be the most significant--at present the acceptance ratio appears to be about .35 .

\section{KGRA Lease Data}

Precise data on the location and physical extent of identified geothermal reservoirs is not currently available. In many cases the reservoir has been defined (by USGS) as a nominal 1.5 square kilometers around a hot spring. In other cases, where the evidence warranted it, a larger area has been ascribed to the reservoir. The definition of these larger reservoirs is not now available. Specific locations (map squares) defining lease sales are available from region offices of the BLM but could not be obtained for this analysis.

Since none of the data needed to analyze the potential of leases within identified reservoirs is available, the KGRA leases have been analyzed by the methods proposed for leased lands associated with but outside identified reservoirs. The methods proposed for lands within a reservoir generally yield a higher estimate of power on line so that the approach taken here is more conservative. 
Leases associated with reservoirs having a temperature below $150^{\circ} \mathrm{C}$ would be likely candidates for non-electric applications. Such leases should be evaluated on a case-by-case basis since they depend on local demand for heat. They have not been evaluated here.

California state lands under lease or under prospecting permits from Reference 4 are stated to be within "potential geothermal areas" but association with specific KGRAs is not given. These data are therefore analyzed by the method described above for KGRA 1 ands not associated with specific reservoirs. The probability of success in finding a resource is also taken to be . 1 .

The estimate of private leasing, given in Reference 8 , of $3,000,000-10,000,000$ acres is also evaluated by the method proposed for lands not associated with an identified resource. Probability of success is taken to be .04 . The range of estimated private leases yields a low and a high estimate of MWe on line. Only the low estimate has been utilized.

The leases held by Union 0il, Magma Power and Thermal Power in The Geysers, of 11,500 acres not currently in use for on-line power generation, have been evaluated using the figure of 700 acres per 100 MWe on 1 ine.*

Scheduled KGRA lease sales through the end of FY 1978 have been evaluated using the method proposed for lands not associated with an

\footnotetext{
${ }^{*}$ Private communication with John P. Finney, Pacific, Gas and Electric.
} 
identified reservoir. Although many of these KGRAs are associated with identified reservoirs, the information needed for that analysis is not all available prior to the sale--specifically price paid per acre--so that the simplifield analysis is more appropriate. 